\title{
Poor quality vital anti-malarials in Africa - an urgent neglected public health priority
}

Paul N Newton ${ }^{1,2,3,4^{*}}$, Michael D Green ${ }^{5}$, Dallas C Mildenhall ${ }^{6}$, Aline Plançon${ }^{7}$, Henry Nettey ${ }^{5}$, Leonard Nyadong ${ }^{8}$, Dana M Hostetler ${ }^{8}$, Isabel Swamidoss ${ }^{5}$, Glenn A Harris ${ }^{8}$, Kristen Powell $^{8}$, Ans E Timmermans ${ }^{9}$, Abdinasir A Amin ${ }^{10}$, Stephen K Opuni ${ }^{11}$, Serge Barbereau ${ }^{12}$, Claude Faurant ${ }^{13}$, Ray CW Soong ${ }^{6}$, Kevin Faure ${ }^{6}$, Jonarthan Thevanayagam², Peter Fernandes², Harparkash Kaur ${ }^{3}$, Brian Angus ${ }^{2}$, Kasia Stepniewska ${ }^{2,14}$, Philippe J Guerin ${ }^{2,4}$ and Facundo M Fernández ${ }^{8}$

\begin{abstract}
Background: Plasmodium falciparum malaria remains a major public health problem. A vital component of malaria control rests on the availability of good quality artemisinin-derivative based combination therapy (ACT) at the correct dose. However, there are increasing reports of poor quality anti-malarials in Africa.

Methods: Seven collections of artemisinin derivative monotherapies, ACT and halofantrine anti-malarials of suspicious quality were collected in 2002/10 in eleven African countries and in Asia en route to Africa. Packaging, chemical composition (high performance liquid chromatography, direct ionization mass spectrometry, X-ray diffractometry, stable isotope analysis) and botanical investigations were performed.

Results: Counterfeit artesunate containing chloroquine, counterfeit dihydroartemisinin (DHA) containing paracetamol (acetaminophen), counterfeit DHA-piperaquine containing sildenafil, counterfeit artemetherlumefantrine containing pyrimethamine, counterfeit halofantrine containing artemisinin, and substandard/ counterfeit or degraded artesunate and artesunate+amodiaquine in eight countries are described. Pollen analysis was consistent with manufacture of counterfeits in eastern Asia. These data do not allow estimation of the frequency of poor quality anti-malarials in Africa.

Conclusions: Criminals are producing diverse harmful anti-malarial counterfeits with important public health consequences. The presence of artesunate monotherapy, substandard and/or degraded and counterfeit medicines containing sub-therapeutic amounts of unexpected anti-malarials will engender drug resistance. With the threatening spread of artemisinin resistance to Africa, much greater investment is required to ensure the quality of ACTs and removal of artemisinin monotherapies. The International Health Regulations may need to be invoked to counter these serious public health problems.
\end{abstract}

\section{Background}

Plasmodium falciparum malaria remains a major public health problem in much of the world, despite decades of interventions [1]. The tragedy remains that many more malaria patients would survive if they had timely access to good quality, affordable and efficacious medicines. With the implementation of pivotal artemisinin-based

\footnotetext{
* Correspondence: paul@tropmedres.ac

'Wellcome Trust-Mahosot Hospital-Oxford University Tropical Medicine Research Collaboration, Microbiology Laboratory, Mahosot Hospital, Vientiane, Lao PDR

Full list of author information is available at the end of the article
}

combination therapy (ACT) throughout malarious Africa and attempts to make it accessible and affordable, hope of controlling malaria has been rekindled [2,3]. Of 42 African countries with $P$. falciparum malaria, ACT is now national policy in 40 (95\%)[4].

A diverse range of important problems reduce ACT effectiveness, including inaccessibility, poor prescribing, poor adherence and poor medicine quality. There are two main categories of poor quality medicine. Counterfeit (or falsified, spurious) medicines (i.e. 'deliberately and fraudulently mislabelled with respect to identity and/or source; $[5,6]$ ) and substandard medicines (i.e. 
'genuine medicines produced by manufacturers authorized.... which do not meet quality specifications set for them by national standards'; $6-8])$. Substandard medicines frequently, and counterfeits occasionally, contain sub-therapeutic amounts of active pharmaceutical ingredients (API) and/or may show suboptimal release of API (dissolution), exposing parasites to sub-lethal concentrations of API(s) [8-10]. However, the percentage API in genuine medicines may also be reduced after manufacture if they are degraded by extremes of temperature and humidity [11].

Substandard and counterfeit anti-malarials were major problems in pre-ACT Africa. Those medicines with subtherapeutic amounts of API are likely to have contributed to the spread of resistance to previous generations of anti-malarials, such as sulphadoxine-pyrimethamine (SP) and chloroquine $[10,12,13]$ (Additional file 1). With evidence that SP and chloroquine-resistant P. falciparum entered Africa from SE Asia [14,15], the recent descriptions of artesunate resistance there [16] suggests that, in addition to major local repercussions, it is very likely to spread to Africa.
There are increasing reports of poor quality artemisinin monotherapies in Africa (Figures 1, 2, Additional file 1). However, monotherapies, even when of good quality, should be replaced by ACTs [1]. Although poor quality ACT has yet to be reported in Asia, there has been an alarming increase in reports of poor quality ACTs in Africa [6,17-23](Additional file 1, Figure 2). Poor ACT quality, along with poor prescribing and poor adherence, would provide a fertile environment for the spread of artemisinin-resistant parasites. This would destroy the renewed hope for malaria control in Africa and killing many patients who would otherwise survive. Therefore, the authors offered to analyse anti-malarial medicines of suspicious quality in sub-Saharan Africa via meetings, INTERPOL and the Counterfeit Drug Forensic Investigation Network (CODFIN [24]).

\section{Methods}

Analyses of packaging, chemistry and botany were performed blindly. The results have been reported using the MEDQUARG guidelines where possible [25]. Samples were stored at $+4^{\circ} \mathrm{C}$ for between 1

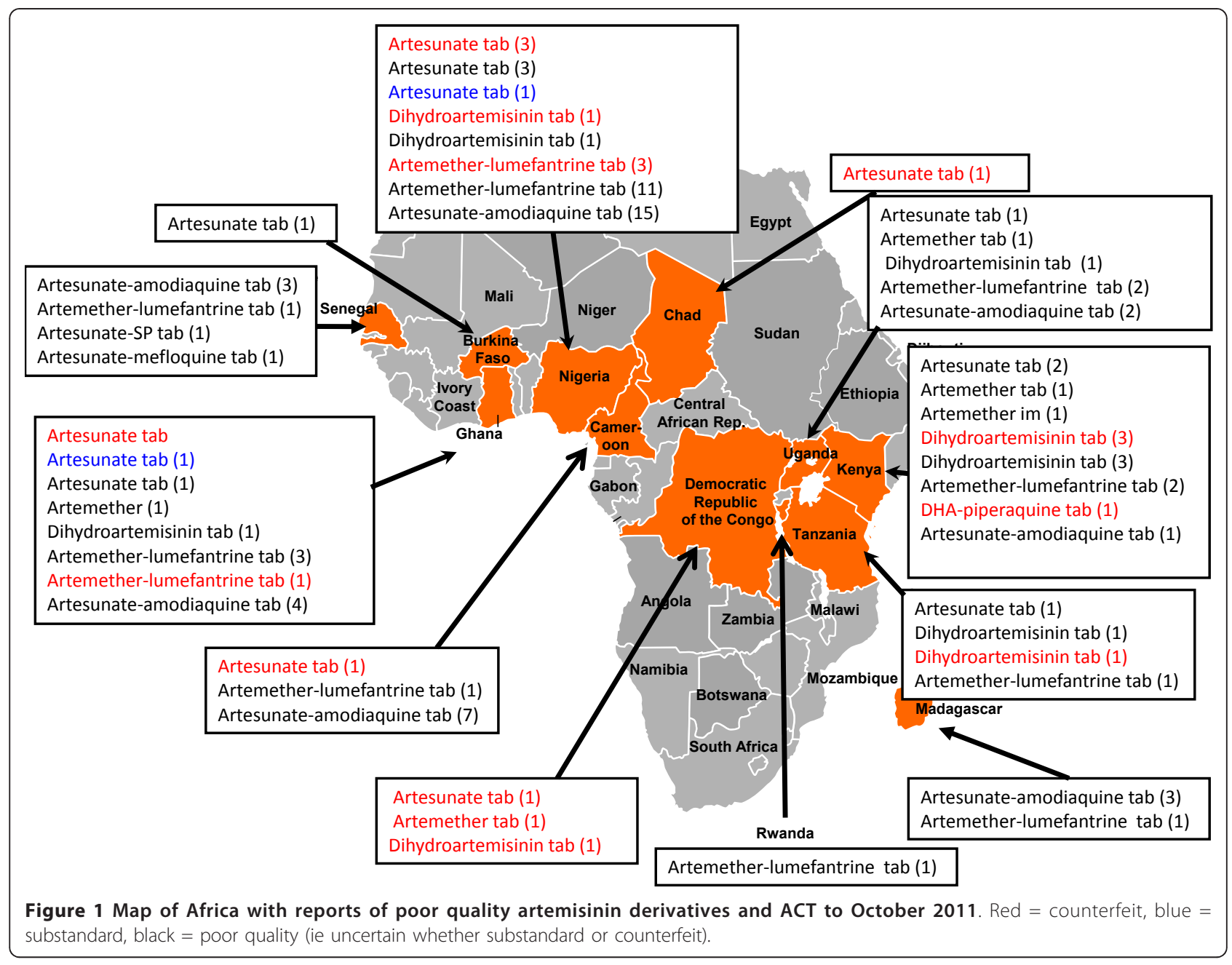


month and 6 years before analysis. Counterfeit, substandard and degraded were defined based on the above definitions, with packaging analysis, in comparison to authentic samples, as the crucial evidence for the distinction between counterfeit and substandard/ degraded. This was performed without any intellectual property considerations. When data did not allow such classification but the sample contained API\% outside reference ranges, such medicines are referred to as 'poor quality'.

\section{Physical appearance}

The physical appearance and text on packaging were examined and compared with known genuine samples when available [26]. Nineteen companies were asked for genuine samples of their products and $6(32 \%)$ responded. DigitalColorMeter (v3.4.1, Apple Inc.) was used to measure the percentage of red (R), green $(G)$ and blue (B) pixels at predefined points on the packaging.

\section{Chemical investigations}

Sample API was quantified using a modified high performance liquid chromatography (HPLC) method with photo diode array detection [27]. Samples were also screened by two direct ionization mass spectrometry (MS) methods: Direct Analysis in Real Time (DART) and Desorption Electrospray Ionization (DESI) in both conventional and reactive modes [28,29]. Select samples were also analysed by X-ray diffractometry (XRD; X'Pert Pro, Philips, Almelo) and isotope ratio MS to determine the mineral composition [26]. GlaxoSmithKline plc (GSK) performed analysis of 'halofantrine' samples using Fourier Transform Infra Red spectroscopy (FTIR), verified when necessary by HPLC with electrospray ionization and mass spectrometry detection (Eckers \& Wolffe pers. comm.)(Additional file 2).

A sample was defined as one dosage unit-such as a blister or blisters in one packet (if present) or one bottle. The \%API range, relative to the stated dosage, allowed on HPLC analysis was $90-110 \%$. An important issue, barely addressed, is that in work such as this, the available sample size of dosage units (such as one blister) is considerably less than that required in testing described in pharmacopoeias [e.g. [30]]. Testing for uniformity commonly requires that if one tablet in a sample contains $<75 \%$ or $>125 \%$ of API relative to the stated dosage, the sample fails the assay [30]. Tablets within this range may represent a Type II error of accepting a sample when it is poor quality. Ignoring the variability in chemical assays, assuming that tablet API\% in an "acceptable" population is normally distributed with standard deviation of $<5 \%$ (to ensure that all tablets are within $75-125 \%$ range) there are, at most, chances of
$1.3 / 1,000,2.3 / 1,000$ and $0.5 / 1,000$ of finding a tablet with 75\%-85\%, 75\%-90\% and 75\%-90\% API, respectively. Therefore, for tablets with API $>75 \%$, taking a pragmatic approach that a sample fails if more than 1 dosage unit falls outside the $90-110 \%$ range, carries a relatively small chance of rejecting a compliant sample or Type I error.

\section{Biological investigations}

Tablet samples were analysed for pollen/spores [26], which could be indicative of either the place of manufacture, the source of the individual ingredients or both, and be influenced by wind dispersal, seasonality and transplantation beyond their known natural range.

\section{Results}

Seven sets of anti-malarials, of ten different types, were collected in eleven African countries 2002-2010 (Table 1 , Additional file 2). The results were reported to the appropriate national Medicines Regulatory Agency (MRA) and the company as stated on the packaging.

\section{Artesunate monotherapy}

Six blisters of 'Mekophar' artesunate tablets were collected in 2007 in Bamenda, Cameroon. All contained chloroquine but no artesunate was detected by HPLC or MS. XRD and botanical analysis suggested that CAM S5/07 had a different source from the other counterfeits. Bulrush (Typha angustifolia) pollen was found in this specimen only, suggesting use of contaminated water or a source near swampland in East Asia or Africa.

The counterfeits were printed with a Nigerian National Agency for Food and Drug Administration and Control (NAFDAC) registration number and a statement that they were marketed by 'Neros Pharmaceuticals Ltd., Lagos, Nigeria', which is the distributor of the genuine product. In comparison to genuine equivalents (Mek 10/03,10/05), the packaging colours and holograms differed and the counterfeit packets were heavier. The genuine hologram was introduced in response to counterfeits but the counterfeit hologram is not similar to those used by Mekophar (Figures 3, 4, 5 and 6, Additional file 3).

In addition, six and one samples of artesunate monotherapy were collected by AET and SB, respectively, in the Democratic Republic of Congo (DRC) in 2007/8. One sample (DRC 08/01) is poor quality with two tablets, stated to contain $100 \mathrm{mg}$ artesunate/tablet, containing 79 and $88 \mathrm{mg}$ artesunate as determined by HPLC. These tablets were analysed 19 months after the expiry date, which could account for the low \%API. Since the packaging contained no manufacturer details, it was not possible to compare with genuine examples but casts doubt on its authenticity. DRC 07/01 (Figure 


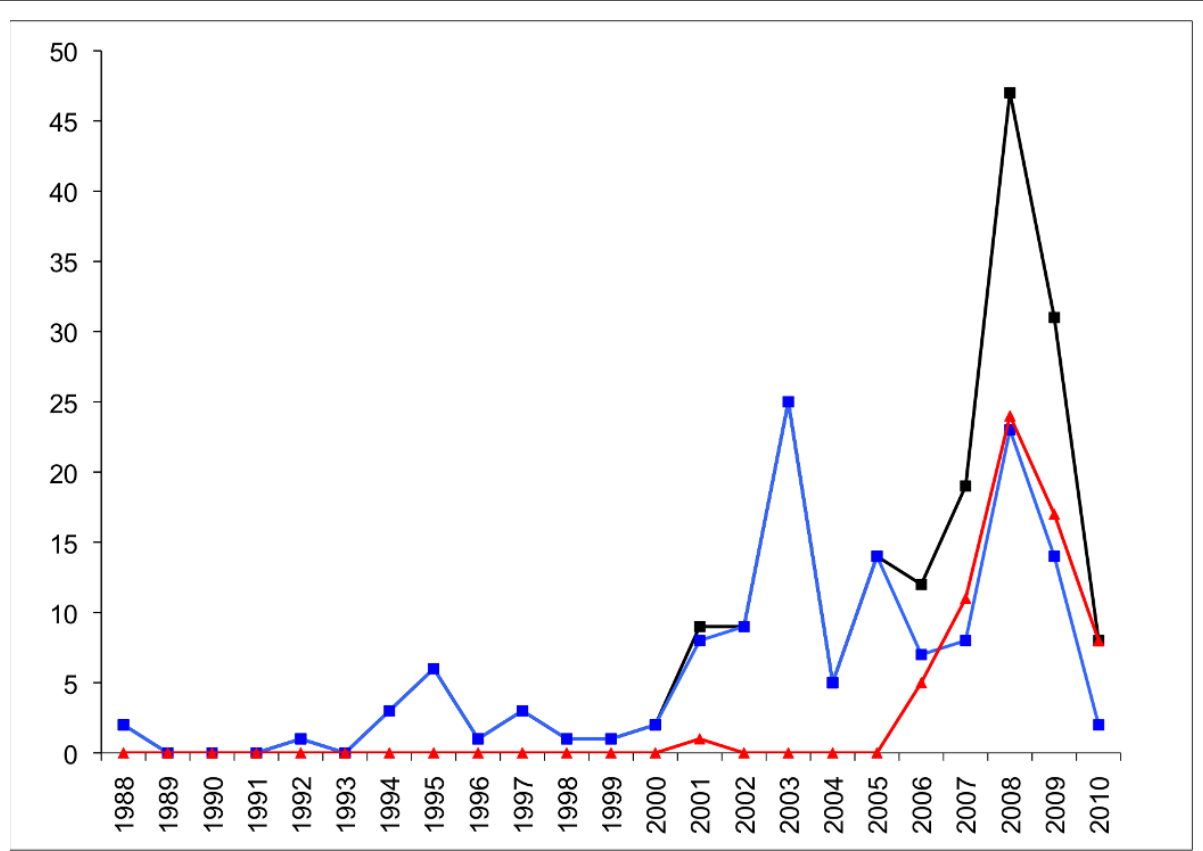

Figure 2 Frequency of reports of poor quality anti-malarials in Africa per year 1988-2010, for all anti-malarials (black), non-artemisinin derivatives (blue) and artemisinin derivative montherapies and ACTs (red). Each poor quality medicine type (by API or brand name per country per report) included. Reports of more than one poor quality medicine of the same brand name/API/formulation per paper classed as one report. The fall in frequency in 2010 is probably an artifact of investigations-up to October 2011 there have already been 64 reports of poor quality anti-malarial types in Africa. See Additional file 1.

7) was counterfeit, stated to be manufactured for 'AT17' in Paris. No evidence was found that this company exists in France. Analysis of this sample showed that it contained 70.9-88.5 mg artesunate/tablet.

In ad hoc sampling in West Africa in 2008 (by JT \& $\mathrm{PF}$ ) of 13 artesunate monotherapies, one (Gh 08/15) had $2 / 4$ tablets outside reference API\% range. The authors were unable to obtain genuine samples of this product and it may be substandard, degraded or counterfeit. An additional six (46\%) samples had one tablet with artesunate content $<90 \%$, relative to the stated dose.

\section{Dihydroartemisinin (DHA) monotherapy}

Two samples labelled as dihydroartemisinin tablets (Cotecxin $^{\mathrm{TM}}$ ) were collected in Kenya in 2007 [23,31]. HPLC analysis gave a DHA content of Kenya 07/01 of $101 \%$, relative to the stated dose whilst no DHA was detected in Kenya 07/02. Only three pollen grains were identified in Kenya 07/01, including Hibiscus species, which are cultivated over many tropical and temperate areas. Kenya 07/02 contained abundant brown fungal spores but only eight pollen grains including Chenopodiaceae pollen, consistent with a source in SE China or in adjacent areas of SE/south Asia but not with Africa. The packaging of Kenya 07/01 and 07/02 were extremely similar. The same differences in tablet size and blister colour as previously described were noted [23].
The counterfeit tablet diameter and blister foil are larger and markedly lighter orange, respectively, than genuine samples (Figures 8 \&9, Additional file 4).

Of the three DHA samples collected during ad hoc sampling in West Africa, although relatively few tablets could be analysed, all had one tablet outside reference \% API range. No differences were detected in the packaging of Gh $08 / 07$ in comparison to samples from the authentic manufacturer. A sample of DHA collected in Nigeria was counterfeit [32] and was found to contain paracetamol (acetaminophen) by MS.

\section{Halofantrine monotherapy}

Eighteen samples of Halfan ${ }^{\mathrm{TM}}$ (halofantrine) tablets, provided by GSK, included two genuine samples and 16 counterfeit examples collected in Sierra Leone (2), Nigeria (9), Cameroon (1), DRC (1), Tanzania (1), Liberia (1) and China (1) in 2002/2007. Of the counterfeit samples, four (25\%) contained artemisinin, seven (44\%) contained acetaminophen, one $(6 \%)$ contained dipyrone, one $(6 \%)$ contained pyrimethamine, one $(6 \%)$ contained halofantrine and no API was detected in two (13\%). Those containing artemisinin were found in Sierra Leone and Nigeria whilst those containing acetaminophen were found in Nigeria, Cameroon, Liberia and China. The median (range) content/tablet of artemisinin was 38 (21-70) $\mathrm{mg}$ and $156(<1-317) \mathrm{mg}$ for 
Table 1 Summary of case reports of poor anti-malarial medicine quality in Africa.

\begin{tabular}{|c|c|c|c|c|}
\hline $\begin{array}{l}\text { Medicine } \\
\text { Country }\end{array}$ & Classification & Stated Manufacturer & Chemistry/Pollen & Packaging/Notes \\
\hline $\begin{array}{l}\text { 'Artesunate' } 50 \mathrm{mg} \\
\text { tablets } \\
\text { Cameroon }\end{array}$ & Counterfeit & $\begin{array}{l}\text { 'Mekophar Chemical } \\
\text { Pharmaceutical Joint-Stock } \\
\text { Company' } \\
\text { Marketed by: 'Neros } \\
\text { Pharmaceuticals Ltd., Lagos } \\
\text { Nigeria' }\end{array}$ & $\begin{array}{l}\text { Contains chloroquine. No artesunate } \\
\text { detected. Pollen grains of bulrush } \\
\text { (Typha angustifolia). Pollen and } \\
\text { chemistry suggests two different } \\
\text { types }\end{array}$ & $\begin{array}{l}\text { Collected because of suspicion of } \\
\text { their low cost ( } 1500 \text { FCFA } \sim \$ 3 / \text { pack } \\
\text { of } 12 \text { tablets). Packet and leaflet } \\
\text { colours and holograms differed and } \\
\text { the counterfeit packets were } \\
\text { heavier. }\end{array}$ \\
\hline $\begin{array}{l}\text { 'Artesunate' } 100 \mathrm{mg} \\
\text { tablets } \\
\text { DR Congo }\end{array}$ & Poor quality & $\begin{array}{l}\text { 'Marinate'. No manufacturers } \\
\text { details on the packaging. Only } \\
\text { 'GUJ/DRUGS/1407' }\end{array}$ & $\begin{array}{l}79 \text { and } 88 \% \text { artesunate/tablet, but } \\
\text { analysed } 19 \text { months after expiry }\end{array}$ & $\begin{array}{l}\text { Probably labeled as made in } \\
\text { Gujerat, India. Genuine packaging } \\
\text { not available }\end{array}$ \\
\hline $\begin{array}{l}\text { 'Artesunate' } 100 \mathrm{mg} \\
\text { tablets } \\
\text { DR Congo }\end{array}$ & Counterfeit & $\begin{array}{l}\text { Astrinate on one face of leaflet } \\
\text { and Arinate on reverse } \\
\text { Stated to be 'Manufactured for } \\
\text { AT17 RUE POISSONNIERS } 75018 \\
\text { PARIS' }\end{array}$ & $88.5,70.9 \mathrm{mg}$ artesunate/tablet & $\begin{array}{l}\text { No agent/company in Rue } \\
\text { Poissonniers. 'Arinate' is the trade } \\
\text { name of artesunate monotherapy } \\
\text { from Dafra Pharma, Belgium. }\end{array}$ \\
\hline $\begin{array}{l}\text { 'Artesunate' } 50 \mathrm{mg} \\
\text { tablets } \\
\text { Ghana }\end{array}$ & Poor quality & $\begin{array}{l}\text { 'LEVER Artesunate' } \\
\text { Stated to be manufactured by } \\
\text { 'ADAMS PHARAMCEUTICAL } \\
\text { (ANHUI) CO., LTD. ANHUI, CHINA } \\
\text { Division of Sunflower Int'l Group' }\end{array}$ & $\begin{array}{l}\text { artesunate } 39.0,43.0,47.0,47.0 \mathrm{mg} / \\
\text { tablet }\end{array}$ & $\begin{array}{l}\text { Unable to obtain sample of genuine } \\
\text { packaging }\end{array}$ \\
\hline $\begin{array}{l}\text { 'Dihydroartemisinin' } \\
60 \text { mg tablets } \\
\text { Kenya }\end{array}$ & Counterfeit & $\begin{array}{l}\text { 'Jiaxing Nanhu Pharmaceutical Co. } \\
\text { Ltd. Jiaxing City, under license of } \\
\text { Beijing Holley-Cotec } \\
\text { Pharmaceuticals (PR China)' with } \\
\text { stated trade name 'Cotecxin' }\end{array}$ & $\begin{array}{l}\text { No dihydroartemisinin detected. } \\
\text { Chenopodiaceae pollen consistent } \\
\text { with a source in SE China or in } \\
\text { adjacent areas of SE and south Asia } \\
\text { but not with Africa }\end{array}$ & $\begin{array}{l}\text { The counterfeit tablet diameter and } \\
\text { blister foil are larger and markedly } \\
\text { lighter orange, respectively }\end{array}$ \\
\hline $\begin{array}{l}\text { 'Halofantrine' } \\
250 \text { mg tablets } \\
\text { Sierra Leone, } \\
\text { Nigeria, Cameroon, } \\
\text { DRC, Tanzania, } \\
\text { Liberia, China }\end{array}$ & Counterfeit & $\begin{array}{l}\text { 'SmithKline Beecham Laboratoires } \\
\text { Pharmacetiques' }\end{array}$ & $\begin{array}{l}\text { One contained correct \% } \\
\text { halofantrine-fraudulent extension of } \\
\text { expiry date. Artemisinin, } \\
\text { acetaminophen, dipyrone, } \\
\text { pyrimethamine wrong APIs. } \\
\text { Fagopyrum (buckwheat) and } \\
\text { Sesamum (sesame) pollen in } \\
\text { counterfeits. Consistent (but does } \\
\text { not prove) with seasonally arid } \\
\text { source in southern China. Betula } \\
\text { (birch) pollen grain and a } \\
\text { Stenochlaena fern spore in other } \\
\text { counterfeits suggesting E/SE Asia, } \\
\text { inconsistent with India/Africa }\end{array}$ & $\begin{array}{l}12 \text { counterfeit Halfan tablets were } \\
\text { classified as Types A, B, C, D, \& E. } \\
\text { Type A contained artemisinin while } \\
\text { B, C, D \& E contained } \\
\text { acetaminophen or no API detected }\end{array}$ \\
\hline $\begin{array}{l}\text { Halofantrine } \\
\text { Syrup } 30 \mathrm{ml} \text { bottle } \\
\text { DR Congo }\end{array}$ & Counterfeit & $\begin{array}{l}\text { 'SmithKline Beecham Laboratoire } \\
\text { Pharmaceutiques Esplanade } \\
\text { Charles de Gaulle } 92731 \\
\text { NANTERRE Cedex,' }\end{array}$ & No API detected & $\begin{array}{l}\text { Came with a spoon, leaflet and } \\
\text { packet, suggesting considerable } \\
\text { investment in deception. }\end{array}$ \\
\hline $\begin{array}{l}\text { 'Dihydroartemisinin- } \\
\text { piperaquine' } \\
40 / 320 \text { mg tablets } \\
\text { China }\end{array}$ & Counterfeit & $\begin{array}{l}\text { 'Zheijiang Holley Nanhu } \\
\text { Pharmaceutical Group Ltd Under } \\
\text { license of HolleyPharm' with } \\
\text { stated trade name 'Duo-Cotecxin' }\end{array}$ & $\begin{array}{l}\text { Sildenafil (Viagra; median (range) } \\
10.4 \text { (6.1-18.4) mg/tablet) detected } \\
\text { in the matrix of the counterfeit } \\
\text { tablets. Cibotium fern, widespread in } \\
\text { SE and south Asia in both } \\
\text { counterfeits and comparator } \\
\text { genuine samples, suggesting that } \\
\text { both manufactured in same region }\end{array}$ & $\begin{array}{l}\text { Packaging with language errors } \\
\text { with English and French (Franglais) }\end{array}$ \\
\hline $\begin{array}{l}\text { 'Artemether- } \\
\text { lumefantrine' } \\
\text { 20/120 mg tablets } \\
\text { Ghana }\end{array}$ & Counterfeit & $\begin{array}{l}\text { 'Beijing Novartis Pharma Ltd, } \\
\text { Beijing, China' }\end{array}$ & $\begin{array}{l}\text { No artemether or lumefantrine } \\
\text { detected. Contain pyrimethamine } \\
(6.2-25 \mathrm{mg} / \text { tablet) and unidentified } \\
\text { yellow pigment in counterfeits. } \\
\text { Pollen in counterfeit samples } \\
\text { consistent with manufacture in E/SE } \\
\text { Asia but not in Africa or India }\end{array}$ & $\begin{array}{l}8 \text { tablets/blister for counterfeits } \\
\text { rather than } 6 \text { for genuine. Errors in } \\
\text { German language spelling }\end{array}$ \\
\hline $\begin{array}{l}\text { 'Artemether- } \\
\text { lumefantrine' } \\
\text { 20/120 mg tablets } \\
\text { Cameroon }\end{array}$ & Counterfeit & $\begin{array}{l}\text { 'Beijing Novartis Pharma Ltd, } \\
\text { Beijing, China' }\end{array}$ & $\begin{array}{l}\text { No artemether or lumefantrine } \\
\text { detected. Contained pyrimethamine } \\
\text { and sulphadiazine }\end{array}$ & 6 tablets/blister for counterfeits \\
\hline $\begin{array}{l}\text { Artesunate \& } \\
\text { amodiaquine co- } \\
\text { blistered. 100/300 } \\
\text { mg tablet } \\
\text { Ghana }\end{array}$ & Poor quality & $\begin{array}{l}\text { 'Pharmanova Limited, Accra, } \\
\text { Ghana. Manufactured by: Atlantic } \\
\text { Pharmaceuticals Limited Accra, } \\
\text { Ghana' }\end{array}$ & $\begin{array}{l}\text { Artesunate } 92.0,103 \mathrm{mg} / \mathrm{tablet} \text { and } \\
\text { amodiaquine } 237,240 \mathrm{mg} / \mathrm{tablet}\end{array}$ & $\begin{array}{l}\text { Unable to obtain sample of genuine } \\
\text { packaging }\end{array}$ \\
\hline
\end{tabular}




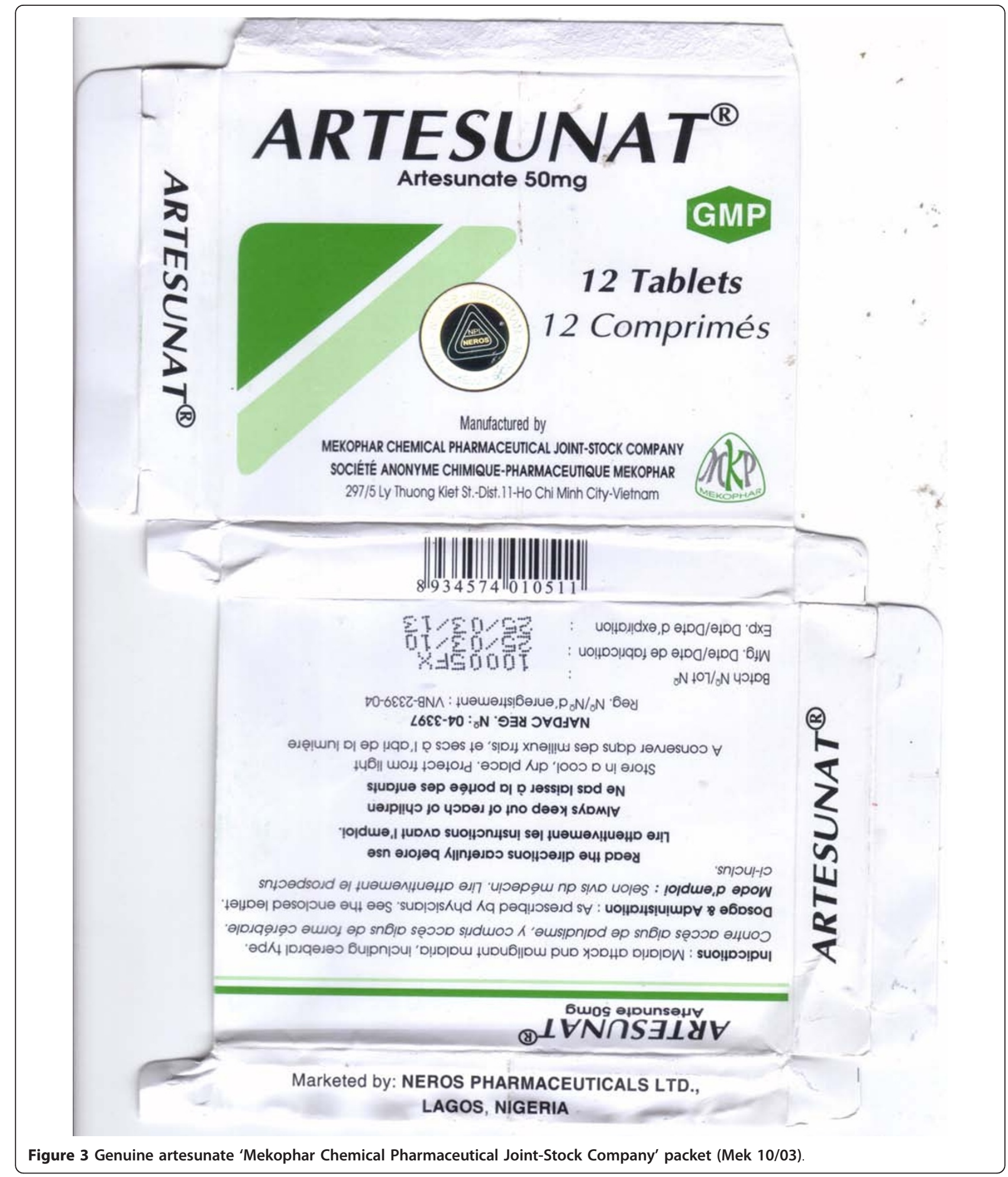

paracetamol. XRD of 4 counterfeits demonstrated diverse excipients with one sample containing only starch and organic compounds (as in genuine 'Halfan') and three containing a variety of combinations of talc, starch and calcite. The sample with only starch and organic compounds detected, contained no detectable pollen and was originally genuine, containing $250 \mathrm{mg}$ halofantrine/tablet, but had manufacturer and expiry 


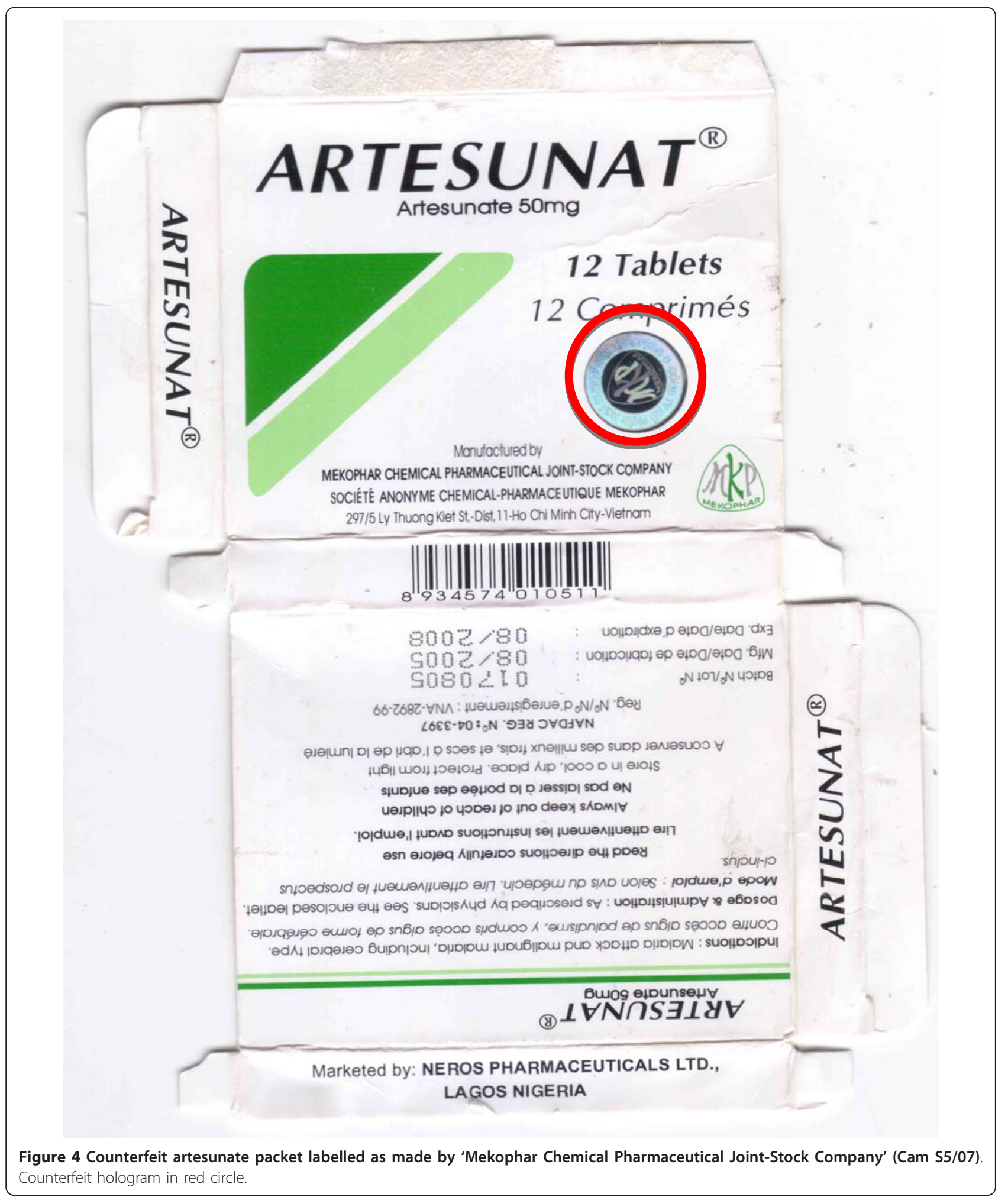

dates fraudulently extended by two years. Thus, pollen, packaging and XRD were able to correctly identify this form of counterfeiting by expiry date tampering. Fagopyrum (buckwheat) and Sesamum (sesame) pollen grains were found in one counterfeit halofantrine sample. Sesame grows in arid areas in India, SE Asia, China and northern Australia, whilst Fagopyrum grows in North America and China. The absence of wind blown grass 


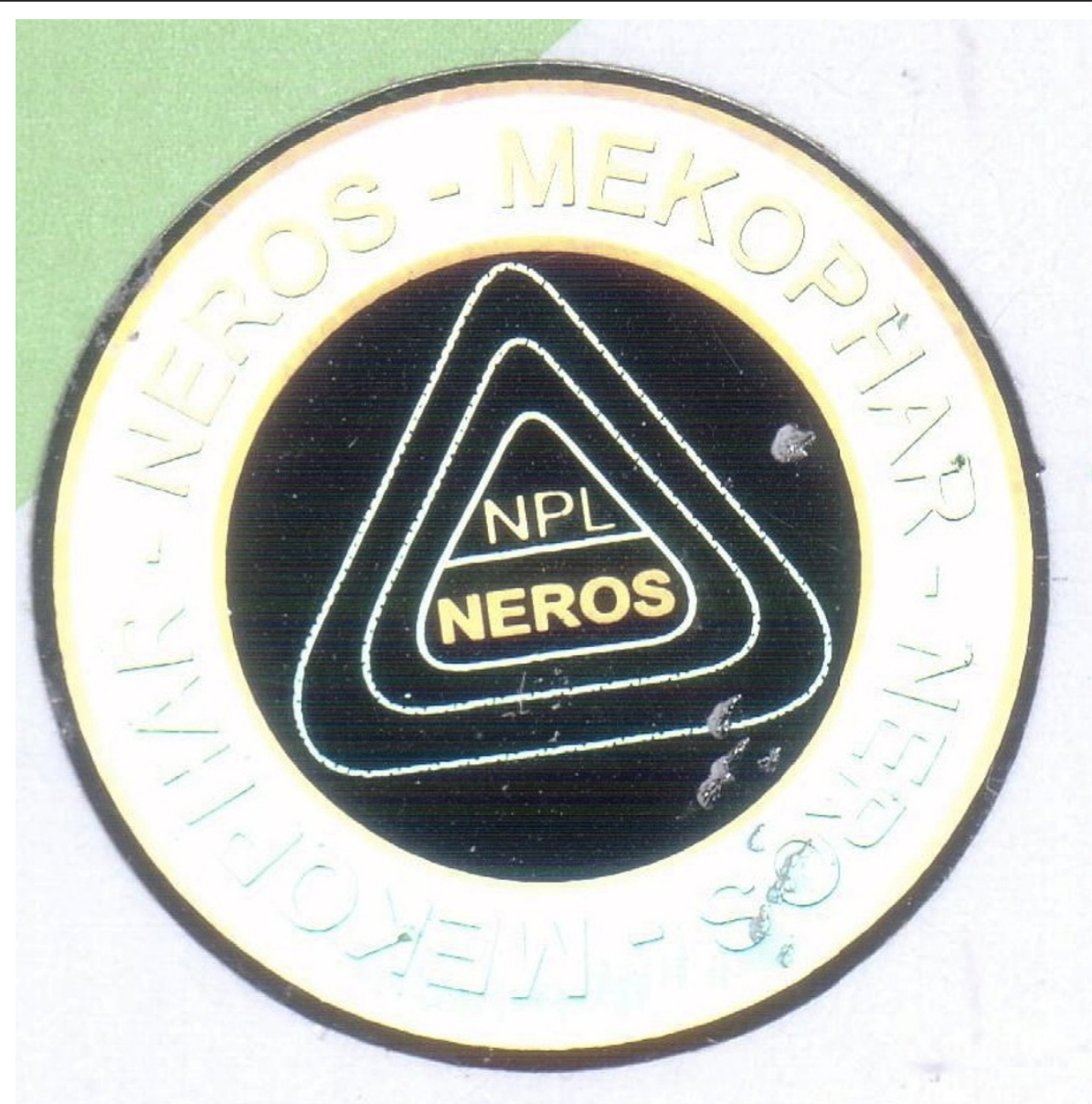

Figure 5 Genuine artesunate with 'Mekophar Chemical Pharmaceutical Joint-Stock Company' and 'Neros' packet hologram (Mek 10/ 03).

pollen suggests a seasonally arid area, consistent with a source in southern China. Another sample contained a Betula (birch) pollen grain and a Stenochlaena fern spore, suggesting East/SE Asia as a source, inconsistent with origins in India or Africa. The packaging of 12 counterfeit Halfan tablets were classified by GSK into Types A, B, C, D, \& E. Type A contained artemisinin while B, C, D \& E contained acetaminophen or no API (Figures 10, 11, 12 and 13).

A sample of counterfeit halofantrine syrup, collected (by SB) in Kivu, DRC, in 2006 had no API detected. Nor did it contain sulphamethazine as previously reported from another counterfeit halofantrine syrup [33]. This came with a spoon, leaflet and packet, suggesting considerable investment in deception.

\section{Dihydroartemisinin-piperaquine ACT}

Eight blisters of co-formulated dihydroartemisinin-piperaquine (Duo-Cotecxin) due to be shipped to Africa from China were provided by Holley-Cotec Pharmaceuticals,
China in 2007. DHA and piperaquine were detected in the four genuine samples but not in the four counterfeit samples. Sildenafil (Viagra; median (range) 10.4 (6.118.4) $\mathrm{mg} /$ tablet) was detected in the matrix of the counterfeit tablets, not in the coating. Botanical analysis of both genuine and counterfeit samples revealed spores of the fern Cibotium, widespread in SE and south Asia, suggesting that both genuine and counterfeit manufacturers were in the same region.

The packaging of four counterfeits contained language errors with English and French combined ('Franglais') e. g. 'Composition par tablet' and 'Dihydroartemisinine' within the English text (Figures 14 \&15, Additional file $5)$. In comparison to the genuine samples, the text was less clearly printed and lacked a hologram. The \%B colour of the blue areas on the packet differed slightly from equivalent areas on the genuine packets $(\mathrm{P}=0.02)$. Both genuine and fake contained blue-coated white tablets and the external tablet colours were similar in terms of RBG\%. The fake tablets were significantly 


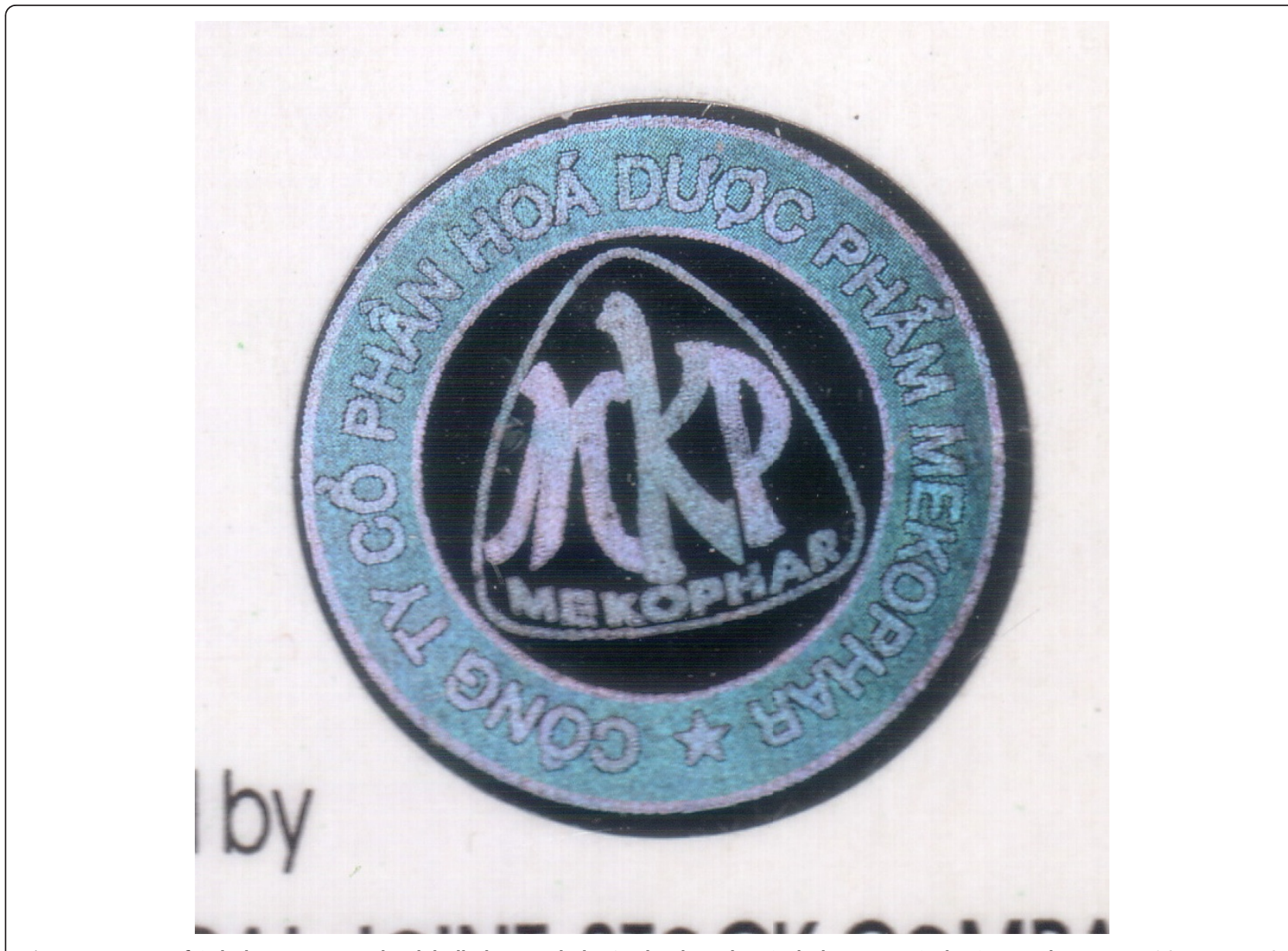

Figure 6 Counterfeit hologram on packet labelled as made by 'Mekophar Chemical Pharmaceutical Joint-Stock Company' (Cam S5/07).

thicker and of significantly narrower diameter than the genuine tablets $(\mathrm{P}=0.02)$.

\section{Artemether-lumefantrine ACT}

The Food and Drug Board, Government of Ghana provided in 2009, via INTERPOL, two packets of 'Coartem' stated to be co-formulated artemether-lumefantrine (eight tablets/blister) and stated to be manufactured by 'Beijing Novartis Pharma Ltd'. Samples of genuine private sector Coartem with eight tablets/blister were not available and therefore a sample bought in Kenya was used as a comparator (Ken 06/01). Both Ghanaian samples contained no detectable artemether or lumefantrine but did contain pyrimethamine $(6.2-25 \mathrm{mg} /$ tablet$)$. All tablets analysed were yellow, which in the case of genuine Coartem results from the presence of lumefantrine. An insoluble (in weak acid) yellow pigment was detected in both counterfeit samples but no amodiaquine, another yellow anti-malarial, was detected by HPLC or MS. The yellow pigment was adsorbed on a nylon filter membrane and eluted with alkaline methanol and had maximum absorbance at $425 \mathrm{~nm}$ but could not be identified by MS. The genuine Coartem samples contained Dacrydium pierrei pollen, a tree growing in southernmost China and in the mountains of northern SE Asia. Pollen in the counterfeit samples were consistent with manufacture in E/SE Asia but not in Africa or India.

The packaging suggested that Gh 09/01 was counterfeit (Figures 16, 17 and 18, Additional file 6). The counterfeiters confused ' $m$ ' with ' $r n$ ' in 'lagern' (German for storing) and printed the packets with the word 'lagem' in error. Initially Gh 09/02 was thought to be genuine, but 8 tablets/blister and smudged codes on the blister implied that it was also counterfeit (Figure 18, Additional file 6), supported by the absence of APIs. The batch numbers of counterfeit 'Coartem' as released by the Food and Drug Board (FDB), Government of Ghana, were X0089 and M1200 [18,19], the same as reported here. Interestingly, it was reported that 'the fake CoArtem contains three strips, each with eight tablets and sold at GH 6.00 while the original one contains four strips with six tablets and sold at Gh 9.00'[18]. That eight tablets were present in each counterfeit Ghanaian blister is further evidence that they were counterfeit, as 


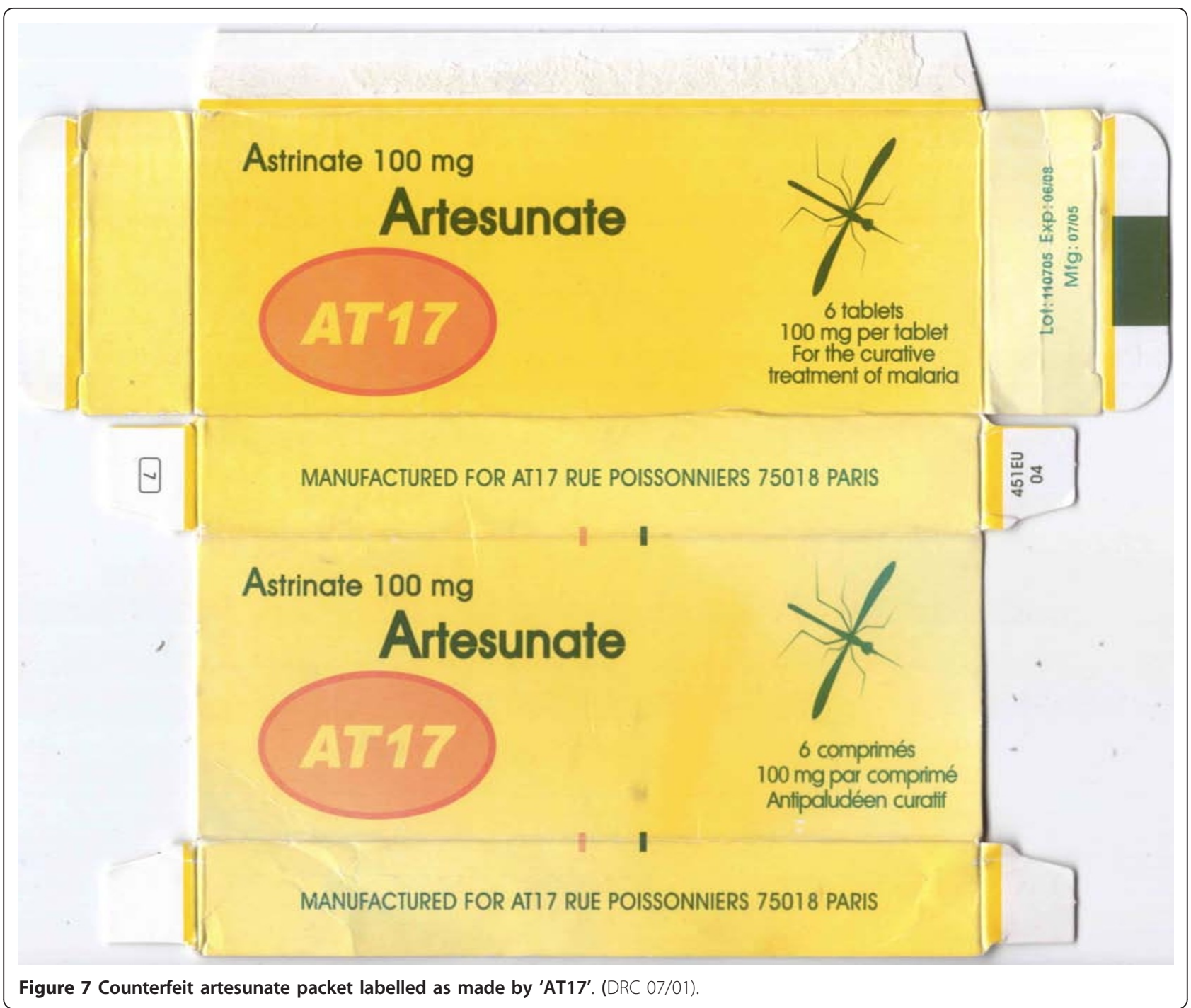

Novartis changed to six tablets/blister in 2007 whilst the samples were labelled as manufactured in 2008 and 2009.

Suspect Coartem from Cameroon were provided via Novartis and INTERPOL in 2010. These consisted of blisters of six tablets, labelled as made in 2008, containing no artemether-lumefantrine, but containing pyrimethamine and sulphadiazine. This suggests that the criminals producing them differed from the counterfeiters operating in Ghana or that they changed their packaging in response to changes made by Novartis.

\section{Artesunate+amodiaquine ACT}

Of one co-blistered artesunate+amodiaquine collected in Ghana, $1 / 2$ pairs of tablets (only 3 pairs per blister) analysed contained less than the reference range for artesunate and amodiaquine and may be counterfeit, substandard or degraded.

\section{Discussion}

This wide diversity of different counterfeit and substandard anti-malarials from eight sub-Saharan African countries are cause of great concern. However, this study has important limitations, especially since it involved ad hoc collection and estimates of the frequency of poor quality anti-malarials cannot be deduced from these data. Tablet dissolution was not measured. The sampling method will bias towards finding counterfeit, rather than substandard, anti-malarials. It provides early warning, worrying for public health, as would a case series of new rapidly fatal epidemic influenza strains. However, that counterfeit formulations of ACT have been found at all is extremely alarming and will increase treatment failure, death and morbidity, yield covert unprotected monotherapy, increase the frequency of anti-malarial drug resistance and produce unexpected and clinically confusing adverse events. That $32 \%$ of 


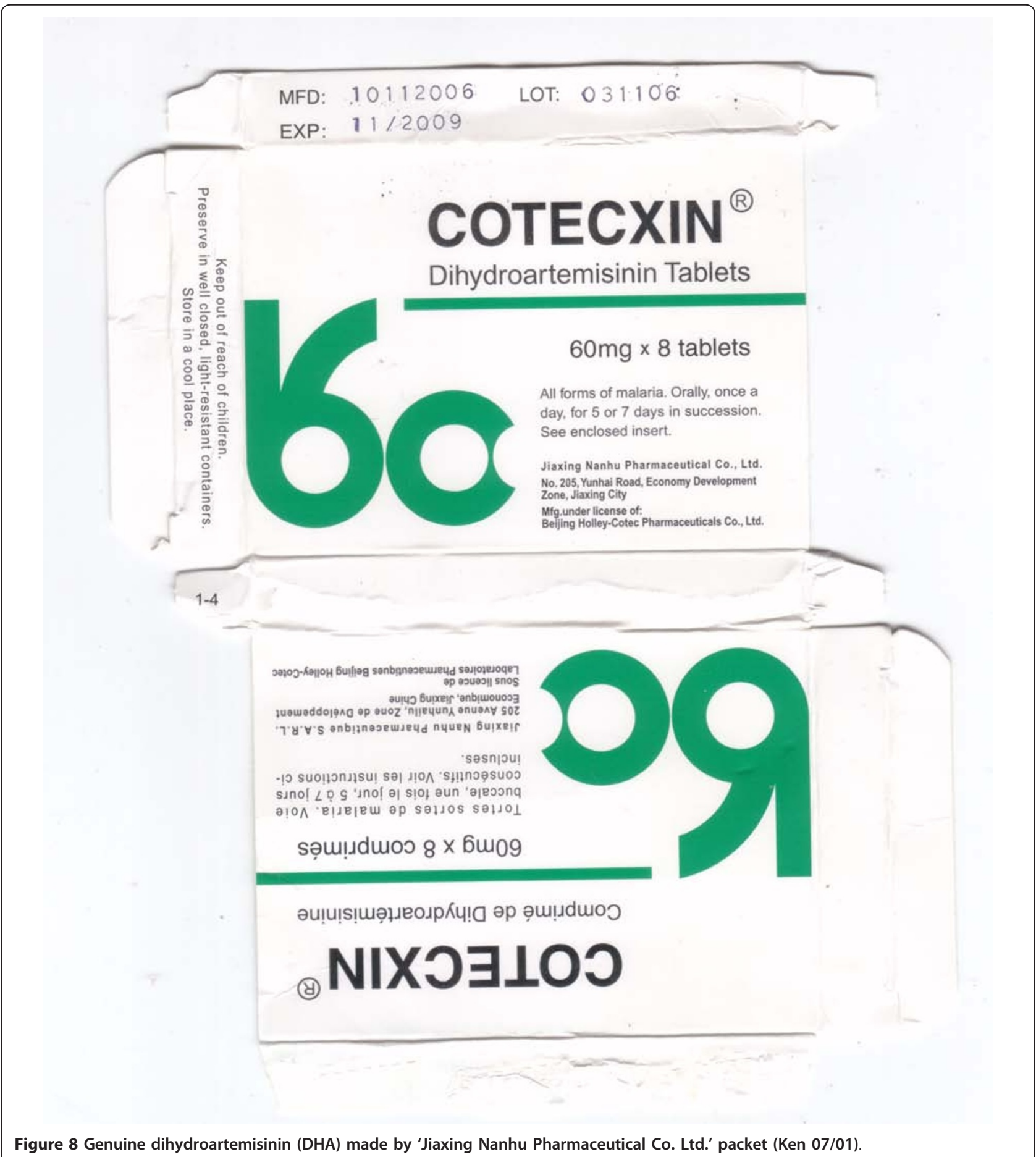

artesunate and all DHA and DHA-piperaquine in the West Africa and DRC collections had one analysed tablet outside \%API reference range is difficult to interpret. Analysis with larger numbers of tablets/sample is needed to understand the clinical implications.

There has been a dramatic rise in reports of poor quality non-artemisinin and artemisinin containing anti- malarials in Africa, suggesting an important worsening situation and/or an emerging interest (Figure 2)[34-36]. There are no data available that allow accurate estimation of the prevalence of poor quality anti-malarials in Africa, but enough information is available to know that it is a serious problem. Public health bodies should not wait for large-scale evidence based on random surveys 


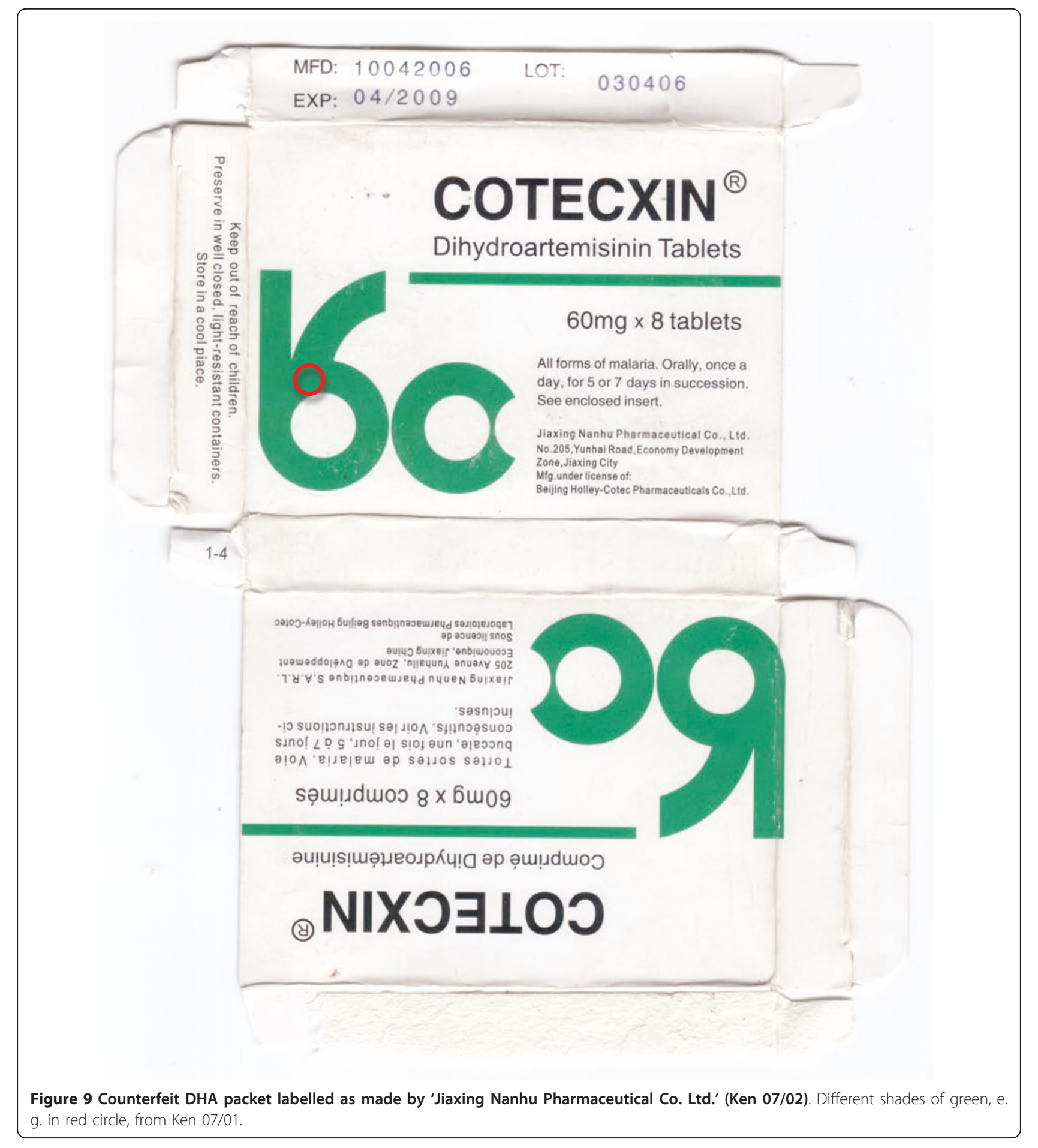

to decide on interventions, as these data will take years to acquire. Unless action is taken quickly, poor ACT quality and profligate use of monotherapy (whether genuine or poor quality) will contribute to the failure of ACT. Although, the correlation between artemisinin resistance and poor drug quality has not been proven, modeling strongly suggests that underdosing is an important factor in the spread of $P$. falciparum drug resistance [13]. Poor quality anti-malarials, usually substandards, resulting in blood concentrations between those that kill resistant and sensitive parasites and those that kill only sensitive parasites will select for drug resistance. Counterfeits may also aid and abet this process by increasing the risk of hyperparasitaemia and 


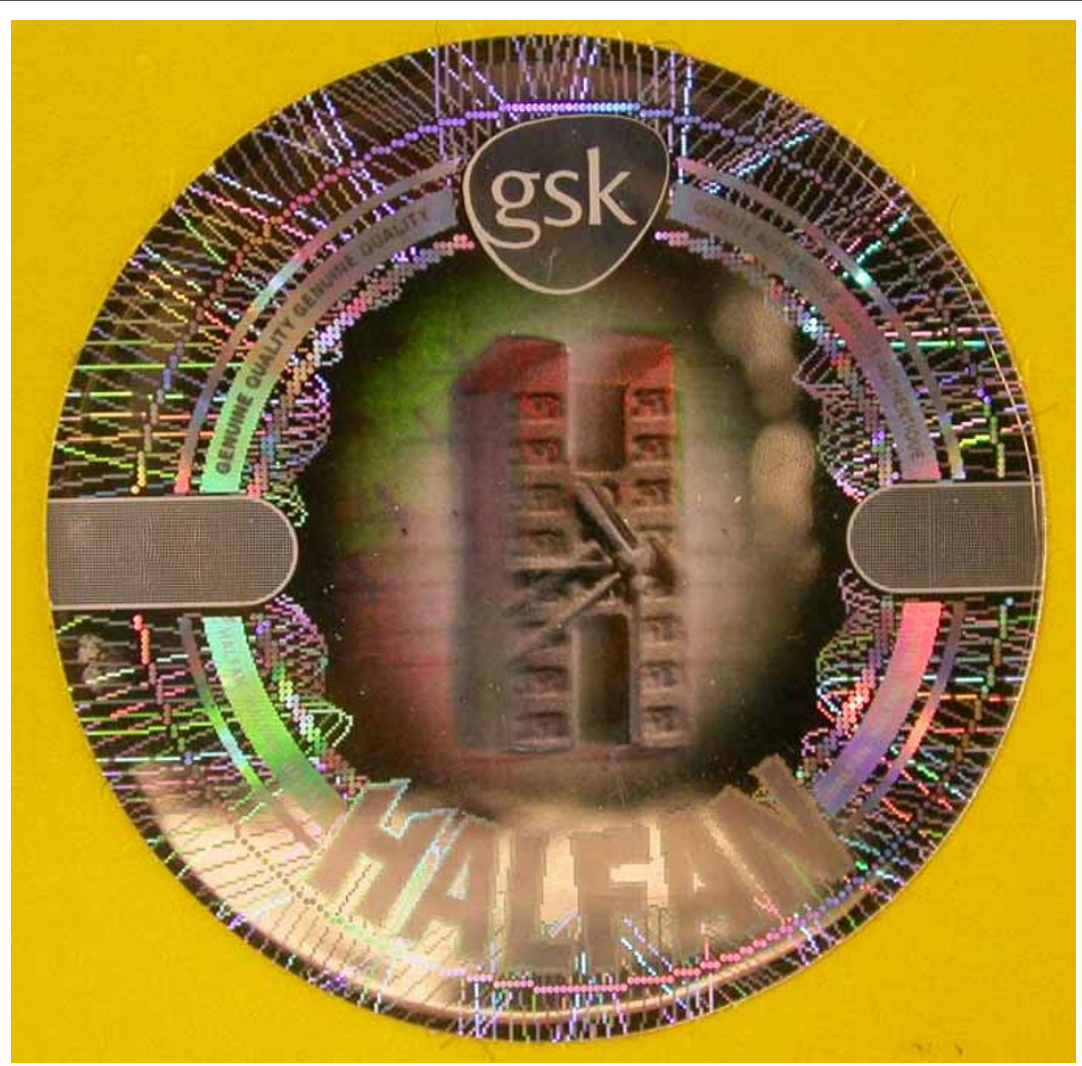

Figure 10 Genuine halofantrine Halfan GlaxoSmithKline hologram.

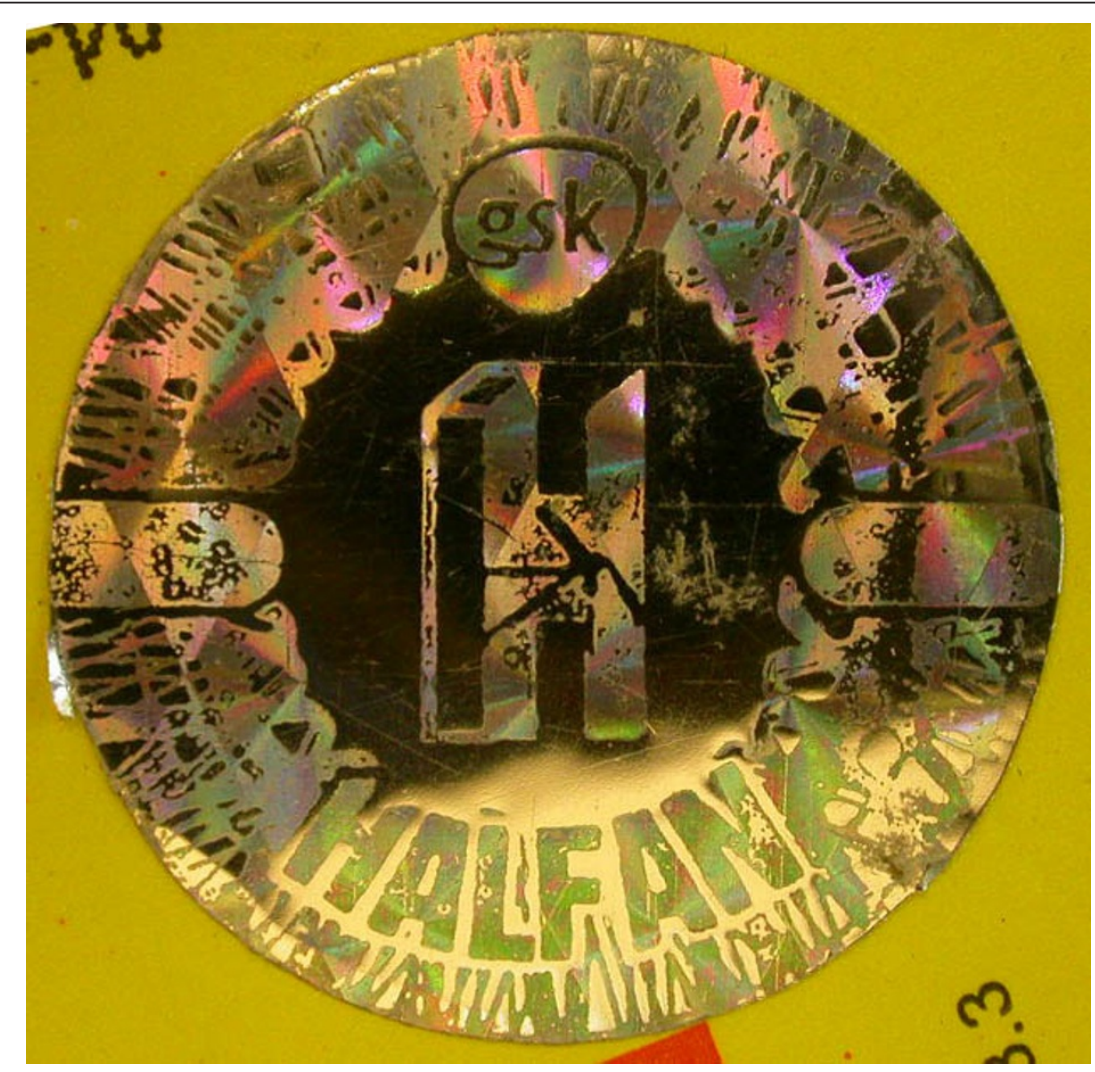

Figure 11 Counterfeit 'Halfan ‘hologram labelled as made by 'GSK' (4040 \& 4023). GSK = GlaxoSmithKline. 


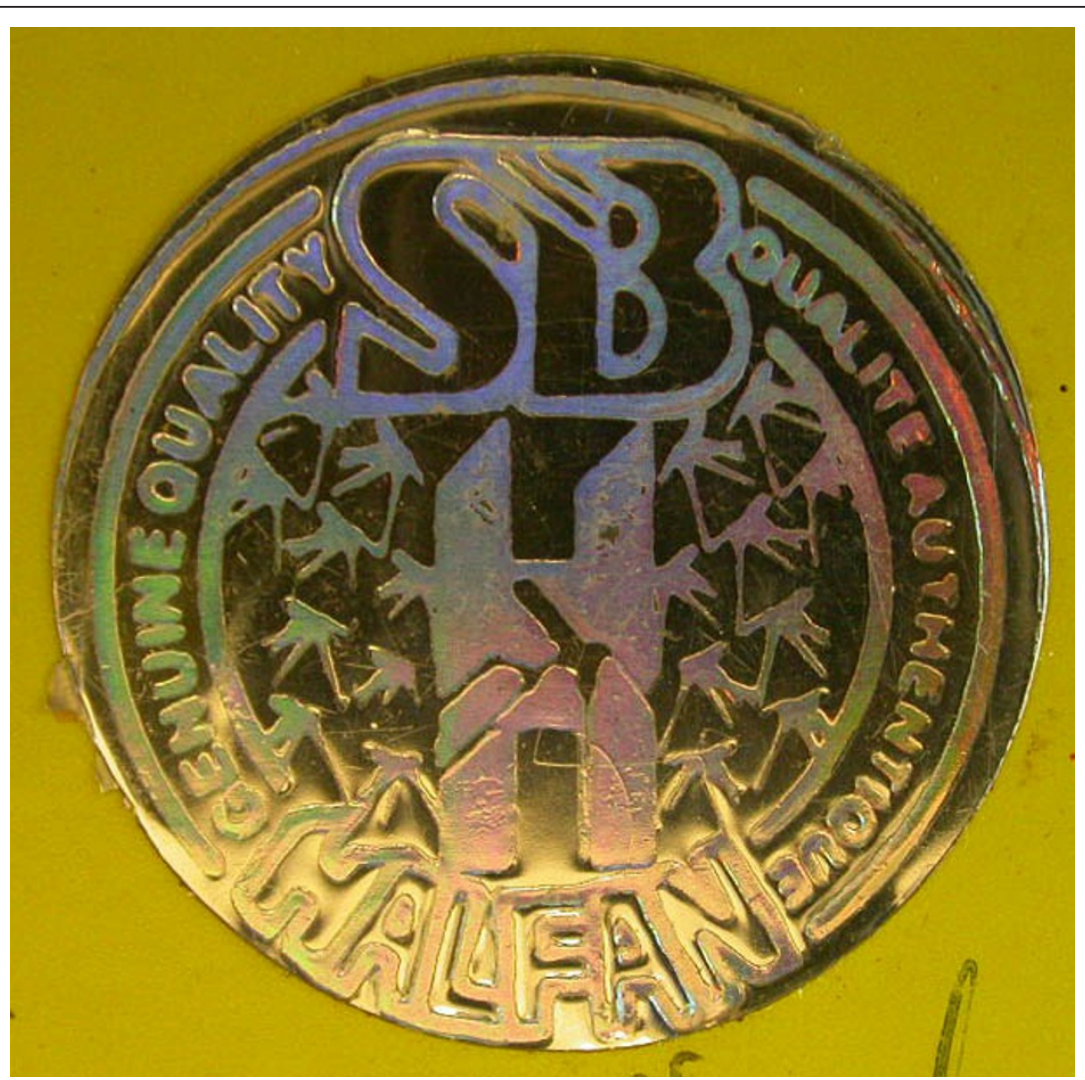

Figure 12 Counterfeit 'Halfan' hologram labelled as made by 'SB' (4024). SB = SmithKline Beecham.

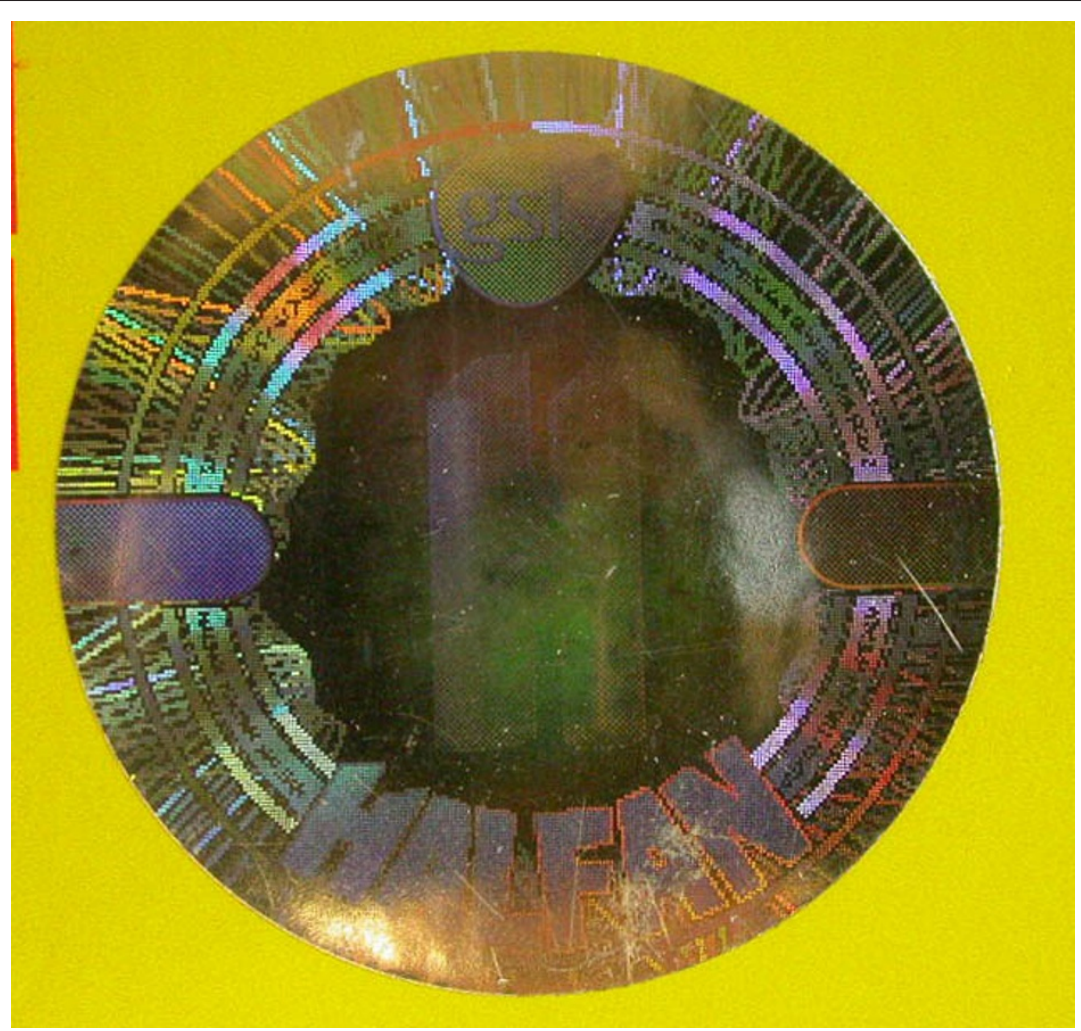

Figure 13 Counterfeit 'Halfan' hologram labeled as made by 'GSK' $(\mathbf{5 0 7 0 , 5 3 1 2 ) . ~ G S K ~ = ~ G l a x o S m i t h K l i n e . ~}$ 


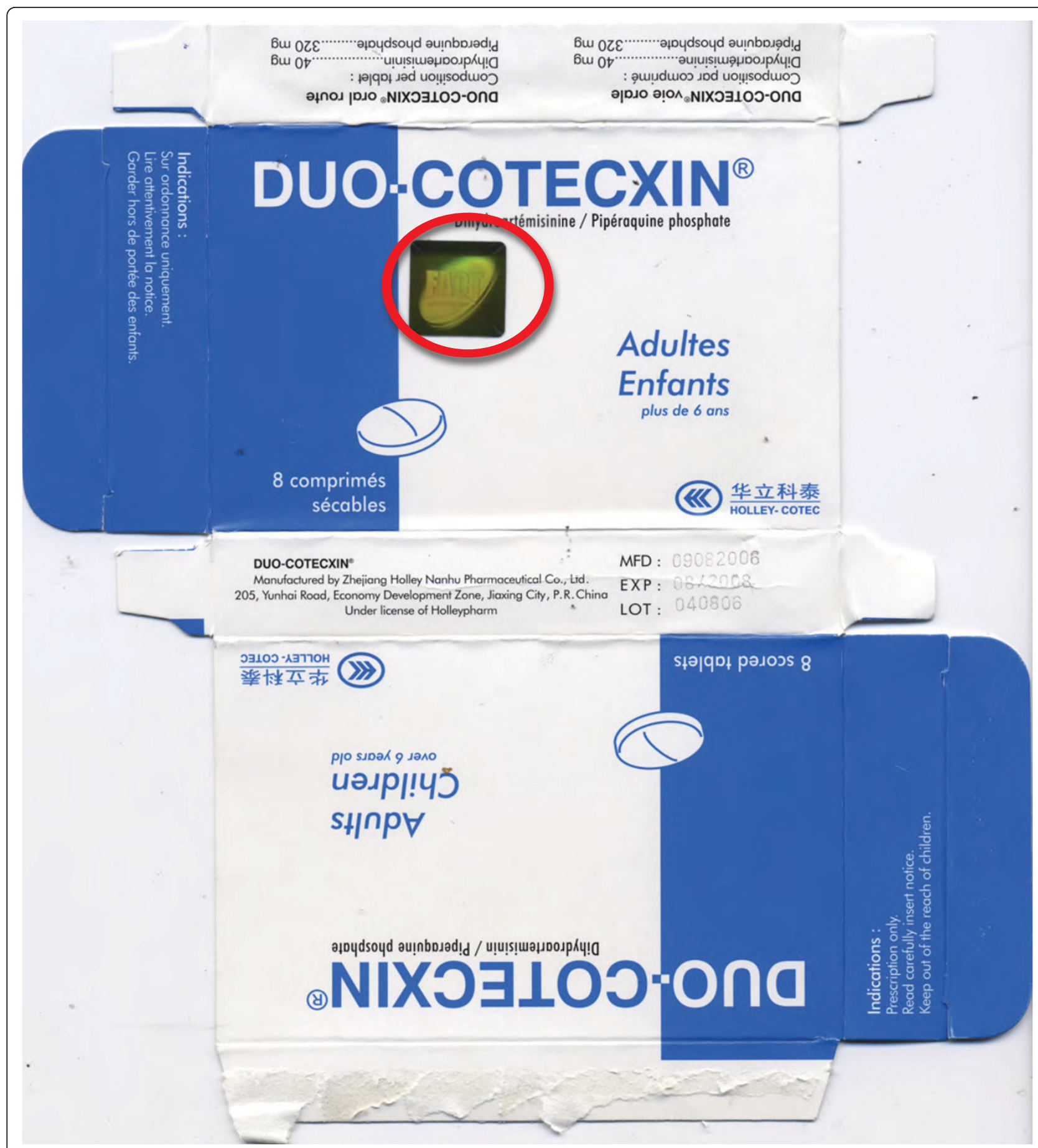

Figure 14 Genuine 'Duo-Cotecxin' dihydroartemisinin-piperaquine packet made by 'Zheijiang Holley Nanhu Pharmaceutical Group Ltd Under license of Holleypharm' (China 07/14). Genuine hologram in red circle.

recrudescence and the co-circulation of substandard and counterfeit medicines may be especially prone to engender drug resistance especially where patients 'shop' around when treatments fail.

The initial misclassification of a counterfeit artemether-lumefantrine as genuine emphasizes the importance of analysing both packaging and the pharmaceutical chemical composition and the importance of access to samples of the authenticated packaging, which was found to be difficult with only $32 \%$ companies responding. In addition, we may have classified counterfeit samples, containing correct \%API, as genuine 


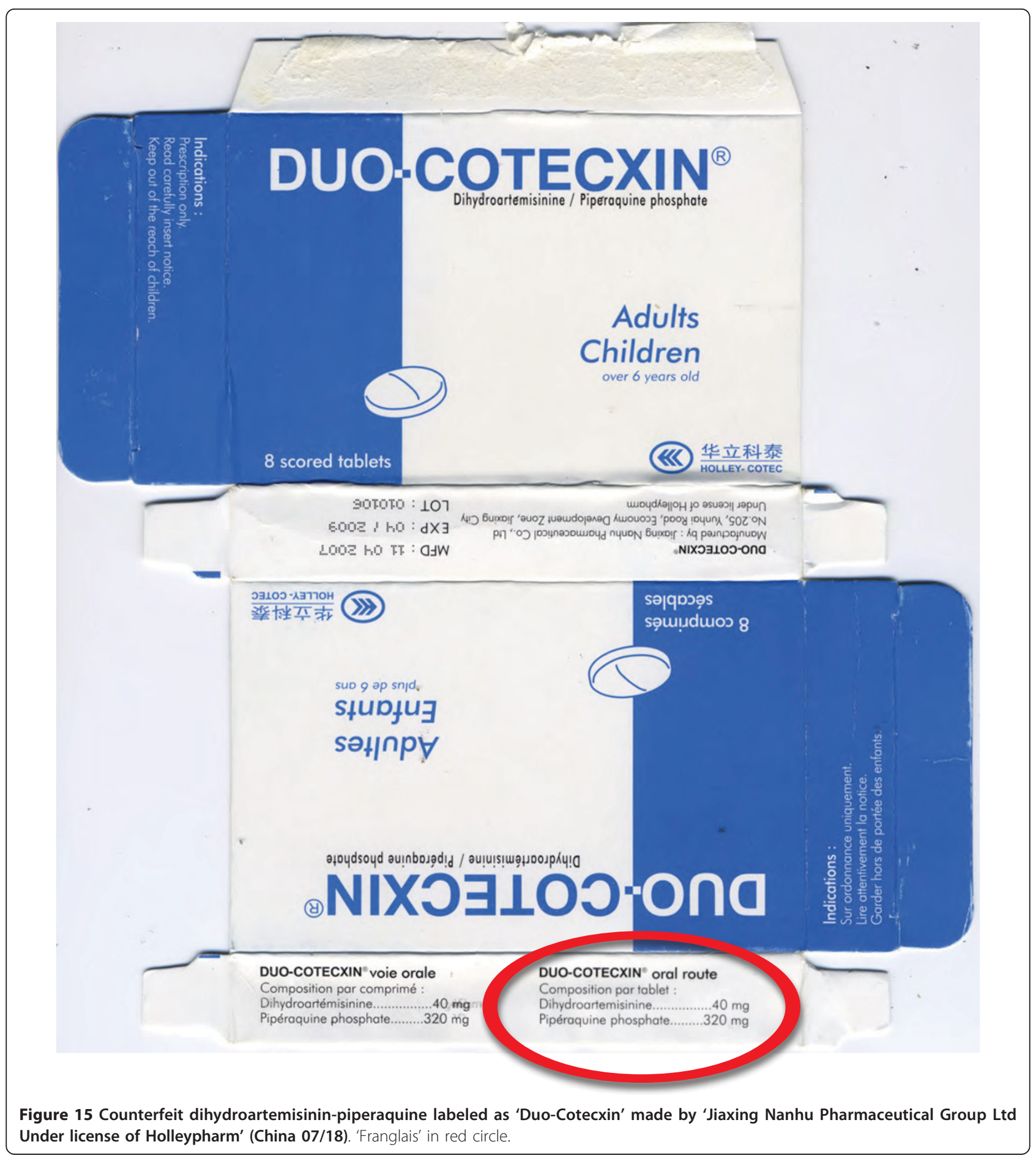

because we were unable to compare all samples with genuine packaging.

The discovery of unexpected APIs in counterfeit antimalarials have important public health implications [37]. Unexpected pyrimethamine, especially if taken repeatedly, could give rise to clinically-confusing adverse effects, such as bone marrow suppression, rash and insomnia [38]. Depending on the background level of $P$. falciparum antifolate resistance [39,40], they may-at least initially-alleviate some malaria symptoms but are extremely unlikely to be curative. Pyrimethamine, in combination with sulphadoxine, is still used in subSaharan Africa, especially for Intermittent Preventive Treatment in pregnancy (IPTp) [4]. The presence of 


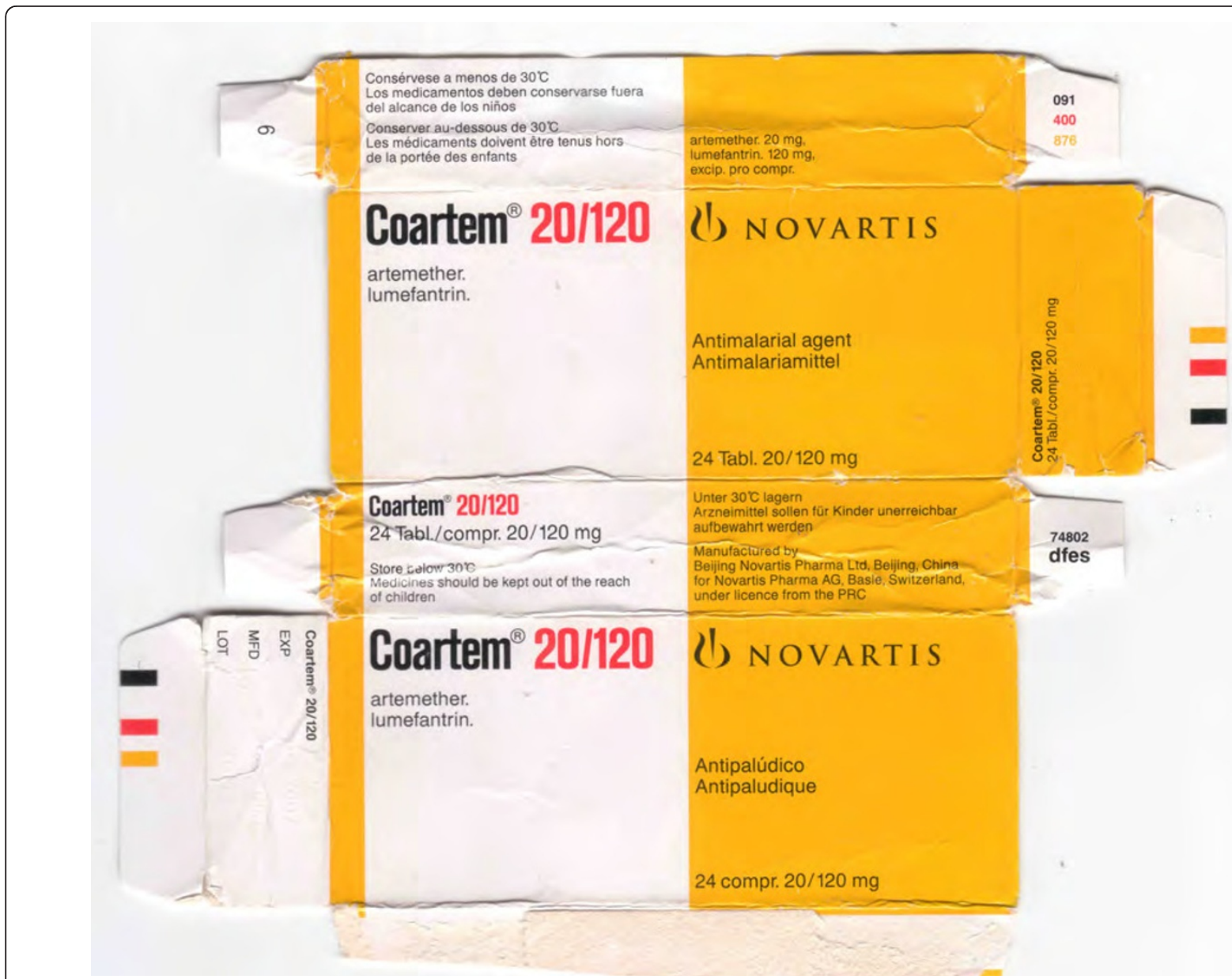

Figure 16 Genuine artemether-lumefantrine 'Coartem' made by ‘Beijing Novartis Pharma Ltd, Beijing, China for Novartis Pharma AG, Basle, Switzerland' (Ken 06/01).

pyrimethamine as hidden monotherapy in counterfeits will engender the further spread of $P$. falciparum dihydrofolate reductase mutations in Africa, increasing therapeutic failure and reducing the useful life of SP for IPTp. Covert consumption of anti-malarials will also confuse our understanding of changes through time of the frequency of clinical failure and molecular markers of chloroquine and SP resistance [39-41]. The median concentration of sildenafil, a wrong API in DHA-piperaquine, was $10.4 \mathrm{mg} /$ tablet, whilst the smallest dose/ tablet of Viagra is $25 \mathrm{mg}$, suggesting that covert administration may cause unexpected penile erection and, as it is not usually taken by the acutely ill, unknown complications. The consequences could be severe especially as this drug is contraindicated in those with hypotension and myocardial ischaemia. In addition, patients may be exposed to dangerous drug interactions between covert consumption and other medicines patients may take, such as sildenafil with anti-HIV medication and chloroquine and pyrimethamine with anti-epileptics [38].
Pollen analyses of the counterfeit anti-malarials were consistent with an origin in eastern Asia, but do not prove this. In 2001 Guangzhou police arrested Nigerian and Chinese men for production of counterfeit halofantrine [42]. No evidence was found, from pollen analysis, of counterfeit pharmaceutical production in Africa. However, production facilities for counterfeit anti-malarial packaging have been seized in Nigeria [43].

What should be done $[6,8,10,12,44]$ ? Multiple parallel strategies are urgently needed to improve the quality of medicines people take and to ensure that they are available and taken at the recommended doses. The enormous investment in the development, evaluation and deployment of anti-malarials is wasted if the medicines that patients actually take are, due to criminality or carelessness, sub-therapeutic. Objective data on the epidemiology of poor quality anti-malarials are needed to allow quantification and mapping of the problem [40], the relative public health importance of counterfeit and substandard 'products', determine intervention 


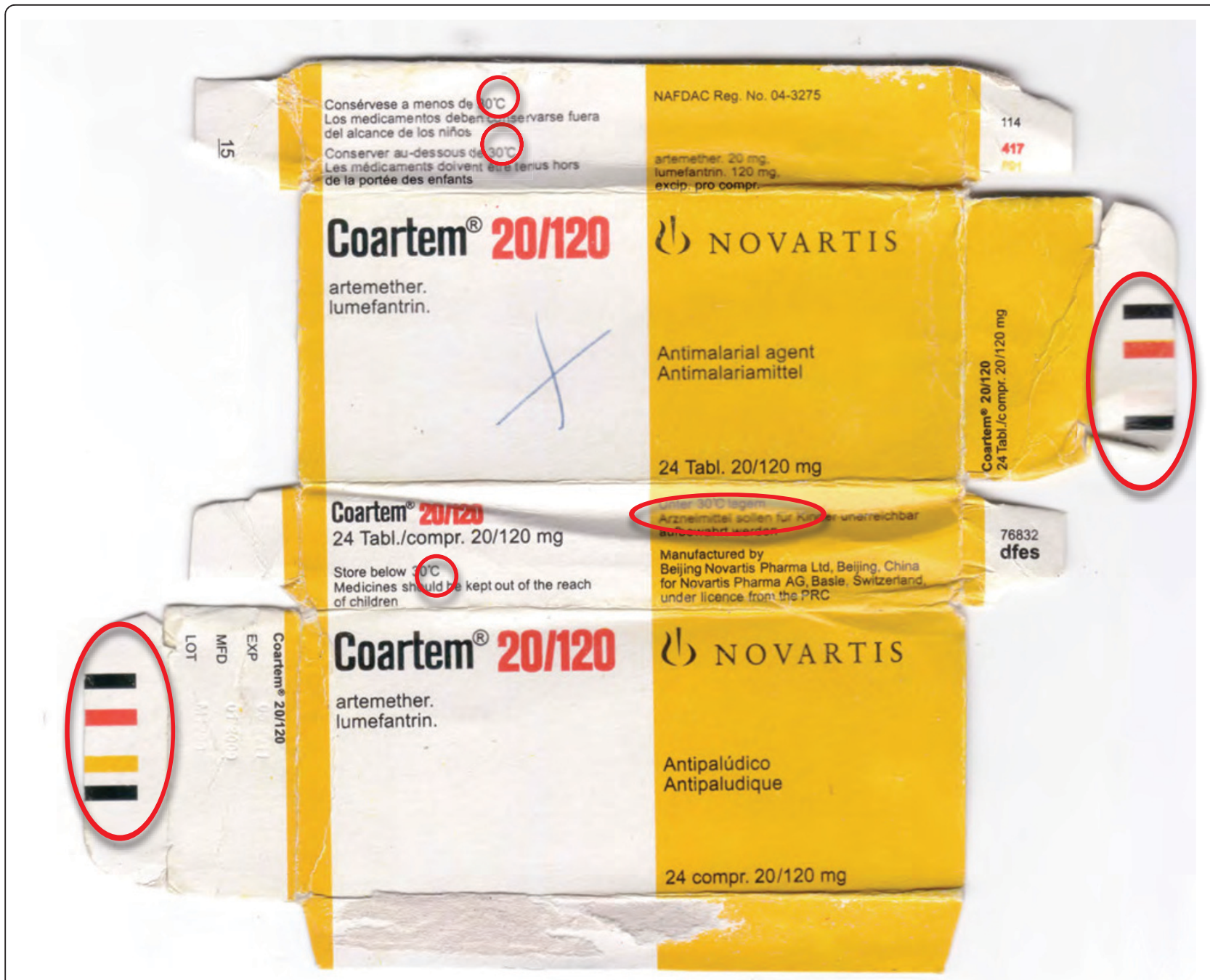

Figure 17 Counterfeit 'Coartem' labelled as made by 'Beijing Novartis Pharma Ltd, Beijing, China for Novartis Pharma AG, Basle, Switzerland' (Gh 09/01). Differences from genuine sample (Figure 16) in red circles.

prioritization and, through following changes through time, evaluate their effectiveness. Second, WHO estimated that $30 \%$ of countries have either 'no drug regulation or a capacity that hardly functions' $[45,46]$ and presumably many of these are economically-poor and malarious. MRAs are keystones for crucial interventions to improve medicine quality and without them most interventions are doomed. There are only three countries with WHO pre-qualified Quality Control medicine analysis laboratories in the whole of malarious Africa [47]. Investment in African MRAs and quality-assured medicine quality laboratories would facilitate countries ability to regulate medicines. There is a danger of poor quality medicines use in clinical trials, likely to bias results and therefore mandatory testing of such medicines should be carried out, preferably at one of the
WHO-prequalified laboratories. Third, increasing the reach of affordable good quality ACT will reduce mortality $[2,3]$ and undercut the counterfeiters, by reducing their profit margins. Stockouts of ACT may encourage poor quality anti-malarial distribution. Fourth, artemisinin monotherapies are still very widely available in large quantities [37,48], despite appeals to restrict their use, and their removal where patients have access to ACT is a key intervention. Fifth, much more attention needs to be paid to substandard medicines, with inspection and facilitation of good quality production. Sixth, increased cooperation between MRAs, police, customs, malaria control programmes, pharmaceutical companies and international organizations is vital in countering the trade in counterfeit medicines. Seventh, new portable and rapid techniques, based on Raman and Near- 


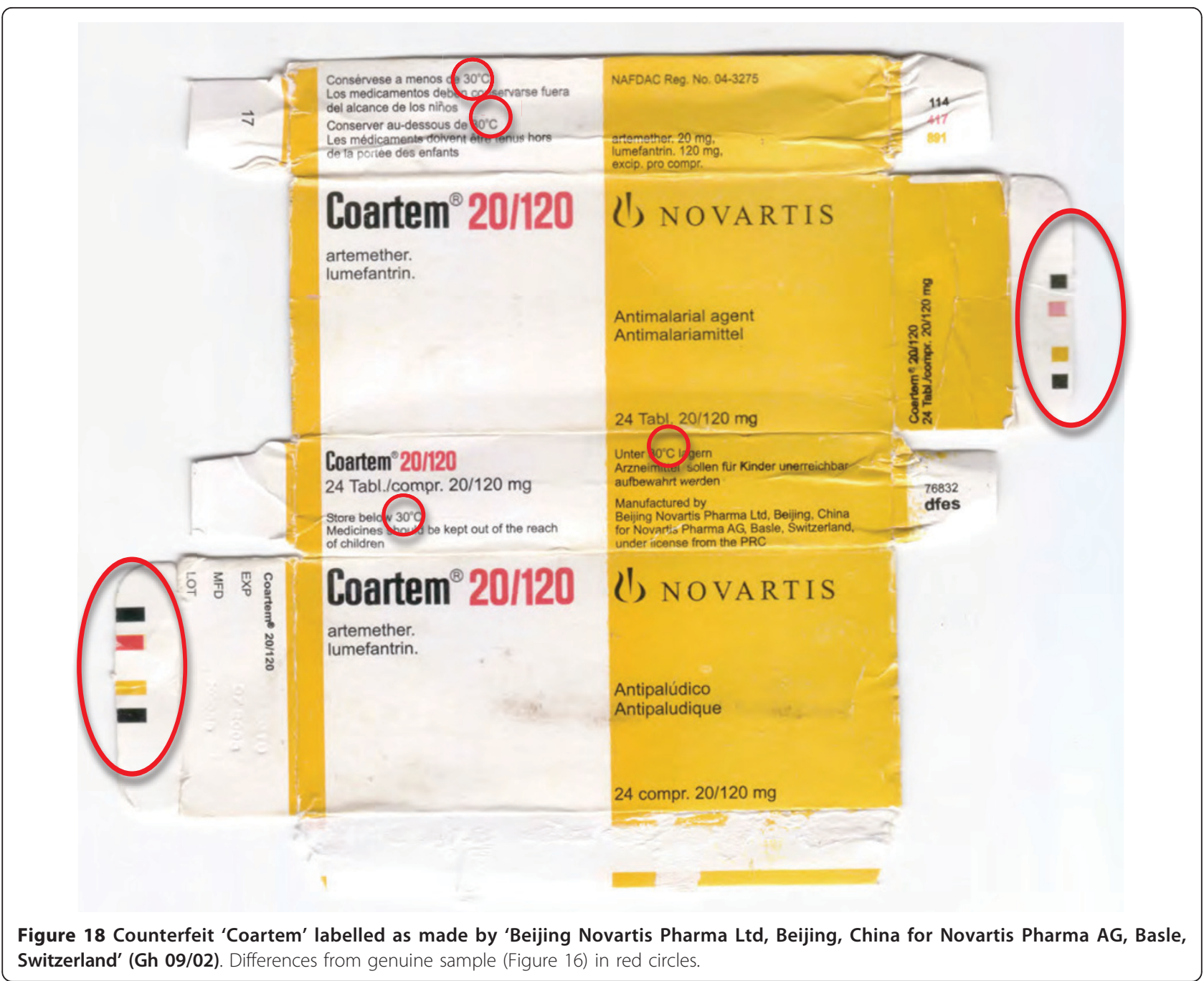

Infrared spectroscopy, have been used in the screening of medicine quality and assisted in recent seizure of imported counterfeit ACT in Nigeria [21]. Although which technique is the most accurate and appropriate remains unclear, they could potentially empower drug inspectors in the screening of pharmacy stock for poor quality medicines. Eighth, we are woefully ignorant as to how best to tackle poor medicine quality in different situations and there has been a damaging lack of public health, civil society and political will to tackle the problem, which those combating the fake Chinchona bark and quinine scandals in the $17^{\text {th }}$ $19^{\text {th }}$ centuries would have found puzzling [10]. Importantly, African heads of state and President Chirac issued the Cotonou Appeal for more action against counterfeit medicines in Africa [49].

With artemisinin resistance in Asia, authorities there have a duty to contain resistant parasites so that they do not spread to Africa. African countries may wish to lobby for more political will in Asia for containment and for financial and human capacity support of African MRAs. The International Health Regulations (IHR)[50] may be a method of facilitating change. In the IHR "disease" means an "illness or medical condition, irrespective of origin or source, that presents or could present significant harm to humans". Poor quality medicines and inappropriate monotherapies-being man-made public health hazards-fall within this definition and the IHR could be invoked to try to stop the spread of poor quality medicines. In addition, a treaty, drafted under the auspices of the WHO, to bring international agreement on interventions to reduce the frequency of both substandard and counterfeit medicines would allow coordinated action [51]. Action is needed immediately or the hopes of controlling malaria in Africa may, again, be dashed.

\section{Conclusions}

The description of a wide diversity of different counterfeit and substandard anti-malarials from eight sub- 
Saharan African countries are cause of great concern. Criminals are producing diverse harmful anti-malarial counterfeits with important public health consequences. The presence of artesunate monotherapy, substandard and/or degraded and counterfeit medicines containing sub-therapeutic amounts of unexpected anti-malarials will engender drug resistance. With the threatening spread of artemisinin resistance to Africa, much greater investment is required to ensure the quality of ACT and removal of artemisinin monotherapies. Support for MRAs is likely to be a key intervention. The International Health Regulations may need to be invoked to counter these poor quality medicines.

\section{Additional material}

Additional file 1: Reports of anti-malarial medicine quality in Africa. Updated from Newton et al (2006a) and Amin \& Kokwaro (2007). Data on medicine stability are not included. If chemical analysis detected API outside reference range, with no wrong API detected, but packaging was not analysed the sample was regarded as poor quality (PQ)-and could represent counterfeit (F), substandard (S) or degraded (D). $C=$ convenience sample, $r=$ convenience sample with some randomization, $\mathrm{R}=$ random sample, $\mathrm{CR}=$ case report, $\mathrm{S}=$ seizure, $\mathrm{WHO}=$ World Health Organization, USP $=$ United States Pharmacopeia. Additional reports kindly provided by Roger Bate.

Additional file 2: Summary of packaging, chemical and botanical analysis of anti-malarial samples. Results for tablets with Al chemical content $<90 \%$ or $>110 \%$ relative to the stated dose in red.

Additional file 3: Features of counterfeit artesunate labelled as made by Mekophar Chemical Pharmaceutical Joint-Stock Company. Distinguishing features in red font.

Additional file 4: Distinguishing features of counterfeit DHA labelled as made by Jiaxing Nanhu Pharmaceutical Co. Distinguishing features in red font

Additional file 5: Distinguishing features of counterfeit DHApiperaquine labelled as made by Zheijiang Holley Nanhu Pharmaceutical Co., Ltd. Distinguishing features in red font. * medians, + medians (range).

Additional file 6: Distinguishing features of counterfeit artemetherlumefantrine labelled as manufactured by Beijing Novartis Pharma Ltd, Beijing, China for Novartis Pharma AG, Basle, Switzerland Distinguishing features in red font.

\section{Acknowledgements and funding}

We are extremely grateful to the many people who have assisted with the collection of samples without which this would not have been possible. We thank Professor TT Hien, Mekophar Chemical Pharmaceutical Joint-Stock Company, Guilin Pharmaceutical Co. Ltd., Denk Pharma GmbH \& Co, Zheijiang Holley Nanhu Pharmaceutical Group Co. Ltd., Bliss GVS Pharma Ltd, Novartis Pharma AG, GlaxoSmithKline plc, Neil Carter, Christine Eckers, Ulrike Fillinger, Jeremy Farrar, Roger Bate, Nicholas J White, Jean-Claude Wolff, the International Rescue Committee (IRC), the ACT Consortium and anonymous collectors for their help and advice. We are very grateful to Patricia Tabernero for checking Additional File 1.

The method development work of FMF was funded by an NSF CAREER grant. LN was partially supported by a USP graduate fellowship. PNN is supported by the Wellcome Trust of Great Britain. Forensic analysis was conducted through the support of the Wellcome Trust and the ACT Consortium, funded by the Bill \& Melinda Gates Foundation to the London School of Hygiene and Tropical Medicine. The funding bodies had no role in the design and conduct of the study and had no role in the decision to publish.

Disclaimer

The opinions and assertions contained herein are the private views of AET and are not to be construed as official or as reflecting the views of the U.S Department of the Army or the Department of Defense.

\section{Author details}

${ }^{1}$ Wellcome Trust-Mahosot Hospital-Oxford University Tropical Medicine Research Collaboration, Microbiology Laboratory, Mahosot Hospital, Vientiane, Lao PDR. ${ }^{2}$ Centre for Tropical Medicine, Nuffield Department of Medicine, University of Oxford, Churchill Hospital, Oxford, OX3 7LJ, UK. ${ }^{3}$ Department of Infectious and Tropical Diseases, London School of Hygiene and Tropical Medicine, WC1E 7HT, UK. "WorldWide Antimalarial Resistance Network, Churchill Hospital, University of Oxford, Oxford, OX3 7LJ, UK. ${ }^{5}$ Division of Parasitic Diseases and Malaria, Center for Global Health, Centers for Disease Control and Prevention, Atlanta, GA, 30329, USA. ${ }^{6} \mathrm{GNS}$ Science, Lower Hutt, 5040, New Zealand. ${ }^{7}$ International Criminal Police Organization (INTERPOL), Lyon, 69006, France. ${ }^{8}$ School of Chemistry and Biochemistry, Georgia Institute of Technology, Atlanta, GA, 30332-0400, USA. 'Department of Immunology and Medicine, Armed Forces Research Institute of Medical Sciences (AFRIMS), Bangkok, 10400, Thailand. ${ }^{10}$ Population Services International, Malaria and Child Survival Department, School Lane, Westlands, P.O. Box 14355-00800, Nairobi, Kenya. ${ }^{11}$ Food and Drugs Board, P O Box CT 2783, Cantonments-Accra, Ghana. ${ }^{12}$ Réseau Médicaments et Développment (ReMeD), 35, rue Daviel, 75013 Paris 13 France. ${ }^{13}$ East West Pharmaceuticals, 189 rue Grande, Fontainebleau, 77300, France. ${ }^{14}$ Mahidol Oxford Research Unit, Faculty of Tropical Medicine, Mahidol University, Bangkok, 10400, Thailand.

\section{Authors' contributions}

AP, AET, AAA, SKO, SB, CF, JT, PF, HK, BA collected and documented samples. MDG, DCM, HN, LN, DMH, IS, GAH, KP, CWRS, KF, FMF performed the chemical/botanical analysis. PN performed packaging analysis. PN and KS performed the statistical analysis. PN, MDG, DCM, AET, PJG, FMF wrote the first draft. All authors revised and approved the final manuscript

\section{Competing interests}

The authors declare that they have no competing interests except CF who owns a consultancy company, East West Pharmaceuticals, which assist Chinese companies in clinical pharmaceutical development.

Received: 22 July 2011 Accepted: 13 December 2011 Published: 13 December 2011

\section{References}

1. World Health Organization: WHO guidelines for the treatment of malaria. Geneva 2010 [http://whalibdoc.who.int/publications/2010/ 9789241547925_eng.pdf], Accessed 12 March 2011.

2. Arrow KJ, Panosian CB, Gelband H: Saving lives, buying time: Economics of malaria drugs in an age of resistance Washington (DC): Institute of Medicine of the National Academies; 2004 [http://www.nap.edu/books/0309092183/ $\mathrm{html} /$, Accessed 12 October 2011.

3. White NJ: Qinghaosu (artemisinin): the price of success. Science 2008, 320:330-334.

4. World Health Organization: Country antimalarial drug policies: by region. Geneva 2009 [http://www.who.int/malaria/

am_drug_policies_by_region_afro/en/index.html], Accessed 12 March 2011.

5. World Health Organization: Executive Board $124^{\text {th }}$ Session Provisional agenda item 4.11. Counterfeit medical products. EB124. Geneva 2008, http://www.who.int/gb/ebwha/pdf_files/EB124/B124_14-en.pdf. With corrigendum-see http://apps.who.int/gb/ebwha/pdf_files/EB124/ B124_14Corr1-en.pdf. Accessed 12 March 2011.

6. Newton PN, McGready R, Fernández F, Green MD, Sunjio M, Bruneton C, Phanouvong S, Millet P, Whitty CJ, Talisuna AO, Proux S, Christophel EM, Malenga G, Singhasivanon P, Bojang K, Kaur H, Palmer K, Day NPJ, Greenwood BM, Nosten F, White NJ: Manslaughter by fake artesunate in Asia-will Africa be next? PLoS Medicine 2006, 3:e197.

7. World Health Organization: What are substandard medicines? Geneva 2009 [http://www.who.int/medicines/services/counterfeit/faqs/06/en/index. html], Accessed 12 March 2011. 
8. Caudron JM, Ford N, Henkens M, Macé C, Kiddle-Monroe R, Pinel J: Substandard medicines in resource-poor settings: a problem that can no longer be ignored. Trop Med Int Health 2008, 13:1062-72.

9. Leslie T, Kaur H, Mohammed N, Kolaczinski K, Ord RL, Rowland M: Epidemic of Plasmodium falciparum malaria involving substandard antimalarial drugs, Pakistan, 2003. Emerg Infect Dis 2009, 15:1753-1759.

10. Newton PN, Fernández FM, Green MD, Primo-Carpenter J, White NJ: Counterfeit and substandard anti-infectives in developing countries. In Antimicrobial Resistance in Developing Countries. Edited by: Sosa AJ, Byarugaba DK, Amábile-Cuevas CF, Hsueh P-R, Kariuki S, Okeke IN. New York, Springer; 2009:413-443.

11. Keoluangkhot V, Green M, Nyadong L, Fernández F, Mayxay M, Newton PN: Impaired clinical response in a patient with uncomplicated falciparum malaria who received poor quality and underdosed intramuscular artemether. Am J Trop Med Hyg 2008, 78:552-555.

12. Amin AA, Kokwaro GO: Antimalarial drug quality in Africa. J Clin Phar Ther 2007, 32:429-440.

13. White NJ, Pongtavornpinyo W, Maude RJ, Saralamba S, Aguas R, Stepniewska K, Lee SJ, Dondorp AM, White LJ, Day NP: Hyperparasitaemia and low dosing are an important source of anti-malarial drug resistance. Malar J 2009, 8:253.

14. Roper C, Pearce R, Nair S, Sharp B, Nosten F, Anderson T: Intercontinental spread of pyrimethamine-resistant malaria. Science 2004, 305:1124.

15. Ariey F, Fandeur $T$, Durand $R$, Randrianarivelojosia M, Jambou R, Legrand $E_{\text {, }}$ Ekala MT, Bouchier C, Cojean S, Duchemin JB, Robert V, Le Bras J, Mercereau-Puijalon O: Invasion of Africa by a single pfcrt allele of South East Asian type. Malar J 2006, 5:34

16. Dondorp AM, Nosten F, Yi P, Das D, Phyo AP, Tarning J, Lwin KM, Ariey F, Hanpithakpong W, Lee SJ, Ringwald P, Silamut K, Imwong M, Chotivanich K, Lim P, Herdman T, An SS, Yeung S, Singhasivanon P, Day NP, Lindegardh N, Socheat $\mathrm{D}$, White $\mathrm{NJ}$ : Artemisinin resistance in Plasmodium falciparum malaria. N Engl J Med 2009, 355:1959-1966.

17. Bate $R$, Coticelli $P$, Tren $R$, Attaran A: Antimalarial drug quality in the most severely malarious parts of Africa - a six country study. PLOS One 2008, 3: e2132.

18. Hope KE: Beware of fake Co-Artem malaria tabs on the market. The Ghanaian Times July 10th 2009.

19. United States Pharmacopeia: Counterfeit antimalarial drug discovered in Ghana with aid of USP Drug Quality and Information Program. 2009, Press release, USP, Available at http://www.usp.org/worldwide/. Accessed 12 March 2011.

20. Udoh F: NAFDAC impounds N10 Million Fake Malaria Drugs. AllAfrica.com 21 Jan 2010

21. Udoh F: Nigeria: NAFDAC impounds consignments of fake drugs valued at N500 Million. AllAfrica.com 10 June 2010.

22. Kwei R: Counterfeit drugs threaten to roll back the gains. Eyes on Malaria (AMREN Magazine) 2009 [http://www.eyesonmalaria.org/fourthedition27. html], Accessed 12 March 2011.

23. The Pharmacy and Poisons Board, Republic of Kenya Ministry of Health: Public Alert. 2007 [http://www.pharmacyboardkenya.org], Accessed 12 March 2011.

24. Counterfeit Drug Forensic Investigation Network-CODFIN. [http://www. codfin.org].

25. Newton PN, Lee SJ, Goodman C, Fernández FM, Yeung S, Phanouvong S, Kaur H, Amin AA, Whitty CJM, Kokwaro GO, Lindegårdh N, Lukulay P, White LJ, Day NPJ, Green MD, White NJ: Guidelines for field surveys of the quality of medicines: a proposal. PLoS Med 2009, 6:e1000052.

26. Newton PN, Fernández FM, Plançon A, Mildenhall DC, Green MD, Ziyong L, Christophel EM, Phanouvong S, Howells S, Mclntosh E, Laurin P, Blum N, Hampton CY, Faure K, Nyadong L, Soong SWR, Santoso B, Zhiguang W, Newton J, Palmer K: A Collaborative Epidemiological Investigation into the Criminal Fake Artesunate Trade in South East Asia. PLoS Med 2008, 5: e32.

27. Green MD, Nettey H, Villalva Rojas O, Pamanivong C, Khounsaknalath L, Ortiz MG, Newton PN, Fernández FM, Vongsack L, Manolin O: Use of refractometry and colorimetry as field methods to rapidly assess antimalarial drug quality. J Pharm Biomed Anal 2007, 43:105-110.

28. Fernández FM, Cody RB, Green MD, Hampton CY, McGready R, Sengaloundeth S, White NJ, Newton PN: Characterization of solid counterfeit drug samples by desorption electrospray ionization and direct-analysis-in-real-time coupled to time-of-flight mass spectrometry. Chem Med Chem 2006, 1:702-705.

29. Nyadong L, Green MD, De Jesus VR, Newton PN, Fernández FM: Reactive desorption electrospray ionization linear ion trap mass spectrometry of latest-generation counterfeit antimalarials via noncovalent complex formation. Anal Chem 2007, 79:2150-2157.

30. The United States Pharmacopeia: The United States Pharmacopeia Washington, D.C., USA. The United States Pharmacopeial Convention; 2005

31. Anon: Malaria drugs recalled in Kenya. BBC News 17 Aug 2007 [http:// news.bbc.co.uk/1/hi/world/africa/6951586.stm], Accessed 12 March 2011.

32. loset JR, Kaur H: Simple field assays to check quality of current artemisinin-based antimalarial combination formulations. PLoS One 2009, 4:e7270.

33. Wolff JC, Thomson LA, Eckers C: Identification of the 'wrong' active pharmaceutical ingredient in a counterfeit Halfan drug product using accurate mass electrospray ionization mass spectrometry, accurate mass tandem mass spectrometry and liquid chromatography/mass spectrometry. Rapid Comm Mass Spect 2003, 17:215-221.

34. INTERPOL: East Africa's Operation Mamba III bolsters fight against counterfeit medicines with INTERPOL-IMPACT support. 26th Aug 2010 [http://www.interpol.int/Public//CPO/PressReleases/PR2010/PR065.asp], Accessed 12 March 2011

35. United States Pharmacopeia: Survey of the quality of selected antimalarial medicines circulating in Madagascar, Senegal, and Uganda. United States Pharmacopeial Convention; 2009 [http://www.usaid.gov/our_work/ global_health/hs/publications/qamsa_report_1109.pdf], Accessed 12 March 2011.

36. World Health Organization: Survey of the quality of selected antimalarial medicines circulating in six countries of sub-Saharan Africa. WHO/EMP/ QSM/2011.1 World Health Organization. Geneva; 2011 [http://www.who.int/ medicines/publications/WHO_QAMSA_report.pdf], Accessed 12 March 2011.

37. Sengaloundeth $\mathrm{S}$, Green MD, Fernández FM, Manolin O, Phommavong K, Insixiengmay $V$, Hampton CY, Nyadong L, Mildenhall DC, Hostetler D, Khounsaknalath L, Vongsack L, Phompida S, Vanisaveth V, Syhakhang L, Newton PN: A stratified random survey of the proportion of poor quality oral artesunate sold at medicine outlets in the Lao PDR-implications for therapeutic failure and drug resistance. Malar J 2009, 8:172.

38. Anon: British National Formulary No 56 BMJ Group and RPS Publishing, London; 2008

39. Drug Resistance Maps. [http://drugresistancemaps.org/].

40. Worldwide Antimalarial Resistance Network:[http://www.wwarn.org/]

41. Laufer MK, Thesing PC, Eddington ND, Masonga R, Dzinjalamala FK, Takala SL, Taylor TE, Plowe CV: Return of chloroquine antimalarial efficacy in Malawi. N Engl J Med 2006, 361:455-467.

42. Anon: GlaxoSmithKline case study. Judicial Protection of IPR in China; 2003 [http://www.chinaiprlaw.com/english/news/news14.htm], Accessed 12 March 2011.

43. Edike T: NAFDAC raids fake drug label printing house. Vanguard (Lagos) 12 Dec 2003.

44. Anon: Combating counterfeit drugs. Lancet 2008, 371:1551.

45. World Health Organization: Counterfeit and substandard drugs. Frequently asked questions. World Health Organization, Geneva; 2005 [http://www.who.int/medicines/services/counterfeit/faqs/en/], Accessed 12 March 2011.

46. World Health Organization: Assessment of medicines regulatory systems in sub-Saharan African countries. World Health Organization, Geneva; 2011 [http://apps.who.int/medicinedocs/en/m/abstract/Js17577en/], Accessed 12 March 2011.

47. World Health Organization: WHO list of prequalified quality control laboratories. World Health Organization, Geneva; 2010 [http://apps.who.int/ prequal/lists/PQ_QCLabsList.pdf], Accessed 12 March 2011.

48. Yeung S, Van Damme W, Socheat D, White NJ, Mills A: Access to artemisinin combination therapy for malaria in remote areas of Cambodia. Malar J 2008, 7:96.

49. Fondation Chirac: The Cotonou Declaration. 2009 [http://www. fondationchirac.eu/en/the-cotonou-declaration-october-12-2009-benin/], Accessed 12 March 2011.

50. World Health Organization: International Health Regulations. World Health Organization, Geneva; 2005 [http://whqlibdoc.who.int/publications/2008/ 9789241580410_eng.pdf], Accessed 12 March 2011. 
51. Attaran $A$, Bate $R$, Kendall $M$ : Why and how to make an international crime of medicine counterfeiting. J Int Criminal Justice 2011, doi:10.1093/ $\mathrm{jicj} / \mathrm{mgr} 005$.

doi:10.1186/1475-2875-10-352

Cite this article as: Newton et al:: Poor quality vital anti-malarials in

Africa - an urgent neglected public health priority. Malaria Journal 2011

10:352.

Submit your next manuscript to BioMed Central and take full advantage of:

- Convenient online submission

- Thorough peer review

- No space constraints or color figure charges

- Immediate publication on acceptance

- Inclusion in PubMed, CAS, Scopus and Google Scholar

- Research which is freely available for redistribution

Submit your manuscript at 